\title{
Probabilistic analysis of maintenance and operation of artificial recharge ponds
}

\author{
Daniele Pedretti ${ }^{\mathrm{a}, *}$, Marco Barahona-Palomo ${ }^{\mathrm{b}}$, Diogo Bolster ${ }^{\mathrm{c}}$, Daniel Fernàndez-Garcia ${ }^{\mathrm{a}}$, \\ Xavier Sanchez-Vila ${ }^{\mathrm{a}}$, Daniel M. Tartakovsky ${ }^{\mathrm{d}}$ \\ ${ }^{a}$ Hydrogeology Group, Department of Geotechnical Engineering and Geosciences, Technical University of Catalonia (UPC-BarcelonaTech), 08034 Barcelona, Spain \\ ${ }^{\mathrm{b}}$ Hydrogeology Group, Department of Geosciences, Institute of Environmental Assessment and Water Research (IDAEA-CSIC), 08034 Barcelona, Spain \\ ${ }^{\mathrm{c}}$ Environmental Fluid Dynamics Laboratories, Department of Civil Engineering and Geological Sciences, University of Notre Dame, IN, USA \\ ${ }^{\mathrm{d}}$ Department of Mechanical and Aerospace Engineering, University of California, San Diego, La Jolla, CA 92093, USA
}

\section{A R T I C L E I N F O}

\section{Article history:}

Available online 27 August 2011

\section{Keywords:}

Managed artificial recharge

Infiltration rate

Clogging

Uncertainty

Probabilistic risk analysis

\begin{abstract}
A B S T R A C T
Aquifer artificial recharge from surface infiltration ponds is often conducted to replenish depleted aquifers in arid and semi-arid zones. Physical and bio-geochemical clogging decreases the host soil's infiltration capacity, which has to be restored with periodic maintenance activities. We develop a probabilistic modeling framework that quantifies the risk of a pond's infiltration capacity falling below its target value due to soil heterogeneity and clogging. This framework can act as a tool to aid managers in optimally selecting and designing maintenance strategies. Our model enables one to account for a variety of maintenance strategies that target different clogging mechanisms. The framework is applied to an existing pond in Barcelona, Spain as well as to several synthetic infiltration ponds with varying statistical distributions of initial infiltration capacity. We find that physical clogging mechanisms induce the greatest uncertainty and that maintenance targeted at these can yield optimal results. However, considering the fundamental role of the spatial variability in the initial properties, we conclude that an adequate initial characterization of the surface infiltration ponds is crucial to determining the degree of uncertainty of different maintenance solutions and thus to making cost-effective and reliable decisions.
\end{abstract}

(c) 2011 Elsevier Ltd. All rights reserved.

\section{Introduction}

Artificial recharge ponds, alternatively called surface infiltration ponds (SIPs), are a popular approach to managed aquifer recharge (MAR) in arid and semi-arid regions $[41,47]$. The effectiveness of SIPs is controlled in large part by the infiltration capacity of the host topsoil, denoted as I. The infiltration capacity affects the total volume of water that can infiltrate into the subsurface and thus the residence time of water within the pond. Since residence time controls important chemical and biological reactions, it plays a significant role in the quality of water being recharged. Spatio-temporal variability of the infiltration capacity at any given site is uncertain due to both soil heterogeneity and pore clogging. To complicate matters further, $I$ is often estimated either directly (e.g., with infiltrometers [42]) or indirectly (e.g., from pore- or grain-size distributions $[12,48]$ ), introducing measurement and interpretive errors as well as a multiplicity of support volumes that can range from a few centimeters to several meters. In the present analysis, we quantify uncertainty in local $I$ by treating it as a spatio-temporal random field.

\footnotetext{
* Corresponding author.

E-mail address: daniele.pedretti@upc.edu (D. Pedretti).
}

Inherent uncertainty in estimates of a SIP's infiltration capacity and predictions of its temporal evolution introduces significant uncertainty into decisions about SIP management, with important economical and environmental implications. Management under uncertainty can be properly formulated within a probabilistic framework context $[25,35,50,53]$. This in turn can form the core of a probabilistic risk analysis, which while a relatively new discipline in hydrogeology [5,9,43,44,22,51,23], forms standard practice in other engineering disciplines (e.g. [34]).

Although the infiltration capacity $I(\mathbf{x}, t)$ generally varies in space $\mathbf{x}$ and time $t$, typically the variable of true interest in managing operations is its spatially-averaged counterpart $\bar{I}(t)$. The latter is related to the former by

$\bar{I}(t)=\frac{1}{V} \int_{\Omega} I(\mathbf{x}, t) \mathrm{d} \mathbf{x}$

where $\Omega$ is the area of the infiltration pond, and $V$ is the corresponding infiltration area.

At a given time, $\bar{I}(t)$ can be estimated either statistically from small-scale local measurements if a sufficient amount of spatiallydistributed data are available, or experimentally with large-scale infiltration tests $[1,4]$. The temporal evolution of $\bar{I}(t)$, typically its reduction, is caused by a combination of physical, biological and 


\section{Nomenclature}

\section{Convention for symbols}

$\langle X\rangle \quad$ stochastic average of $X$

$\mathbf{X}=(x, y)^{T}$ horizontal coordinate vector $[\mathrm{L}]$

$\bar{X} \quad$ spatial average of $X$

$t \quad$ time $[\mathrm{T}]$

$X_{0} \quad X$ taken at time $t=0$

$z \quad$ vertical coordinate [L]

\section{Symbols}

$\kappa \quad$ soil permeability $\left[\mathrm{LT}^{-1}\right]$

$\lambda_{\text {eff }} \quad$ effective decay (clogging) rate $\left[\mathrm{T}^{-1}\right]$

$\lambda_{b} \quad$ biological clogging factor $\left[\mathrm{T}^{-1}\right]$

$\lambda_{s} \quad$ characteristic microbial growth parameter $\left[\mathrm{T}^{-1}\right]$

$\lambda_{z} \quad$ filtration coefficient $\left[\mathrm{L}^{-1}\right]$

q the flow velocity of water [LT ${ }^{-1}$ ]

$\mu_{w} \quad$ dynamic viscosity of water $\left[\mathrm{ML}^{-1} \mathrm{~T}^{-1}\right]$

$\Omega \quad$ area occupied by the infiltration pond $\left[\mathrm{L}^{2}\right]$

$\phi \quad$ soil porosity [-]

$\phi_{b} \quad$ porosity occupied by biomass [-]

$\rho_{b} \quad$ biomass density $\left[\mathrm{ML}^{-3}\right]$

$\rho_{k} \quad$ the bulk density of the soil $\left[\mathrm{ML}^{-3}\right]$

density of water $\left[\mathrm{ML}^{-3}\right]$

variance of $Y\left[\mathrm{~L}^{2} \mathrm{~T}^{-2}\right]$

geometrical coefficient for the Hazen formula [-]

volumetric concentration of particles $\left[\mathrm{ML}^{-3}\right]$

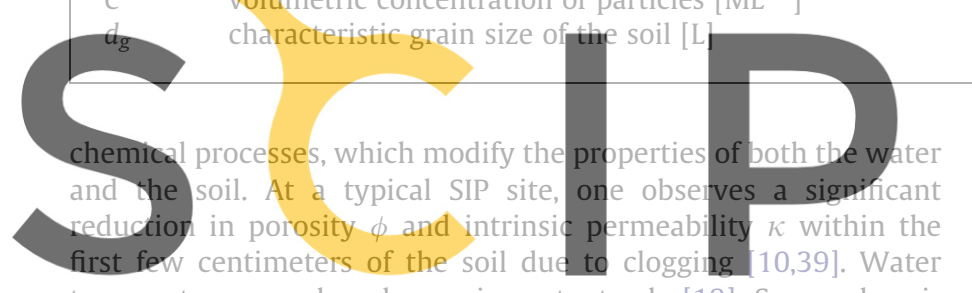

temperature can also play an important role [18]. Seasonal variations in the density and viscosity of water may contribute to

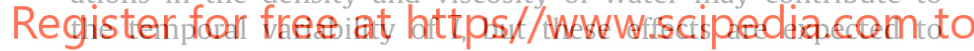

be secondary and act on much larger time scales (months) than those relevant to clogging (days)

Depending on the overall intensity of the clogging mechanisms, SIPs can suffer from "aging" [33], which is an appreciable reduction in the infiltration capacity $\bar{I}(t)$, in the first few days after flooding. To meet designed infiltration rates, SIPs must be periodically maintained with either preventive or corrective measures [2,14]. The speed with which $\bar{I}(t)$ approaches or drops below some critical threshold value $I_{c}$ is the primary variable indicating when and what type of corrective measures should be taken.

The goal of our analysis is to provide a framework to evaluate the engineering risk of making decisions in regards to optimal maintenance of SIPs, when spatio-temporal distributions of local hydraulic properties of the topsoils are uncertain. We adopt a probabilistic approach that treats the relevant hydraulic parameters as random fields and renders the governing equations stochastic. Section 2 provides a justification for adopting this probabilistic approach. The main factors and their modeling formulations are described in Section 3. Section 4 contains a general sensitivity analysis of the selected models. In Section 5, this methodology is applied to one real and a few synthetic examples.

\section{Operation of SIPs under uncertainty}

The complexity of modeling soil clogging and the corresponding reduction in infiltration capacity, coupled with ubiquitously $d_{m} \quad$ percentile of the cumulative distribution of the soil grain sizes [L]

$d_{s} \quad$ mean diameter of suspended particles in the water during the flooding stage [L]

$d_{10}$ tenth percentile of the cumulative distribution of the soil grain sizes $[\mathrm{L}]$

g gravity acceleration constant $\left[\mathrm{LT}^{2}\right]$

$h \quad$ hydraulic head [L]

I infiltration capacity $\left[\mathrm{LT}^{-1}\right]$

$I_{c} \quad$ the smallest acceptable $\bar{I}(t)\left[\mathrm{LT}^{-1}\right]$

$I_{S} \quad$ correlation length for local $Y$ values (in pixels) [-]

$K \quad$ saturated hydraulic conductivity $\left[\mathrm{LT}^{-1}\right.$ ]

$K_{b} \quad$ Boltzmann constant $\left[\mathrm{L}^{2} \mathrm{MT}^{-1} \mathrm{~K}^{-1}\right]$

$M_{b} \quad$ relative biomass attached to the soil [-]

$n$ geometrical parameter for clogging interception mechanisms [-]

$R \quad$ reduction factor for gas clogging $[-]$

T $\quad$ water temperature [K]

$v_{a} \quad$ average particle's attachment velocity to the soil matrix $\left[\mathrm{LT}^{-1}\right]$

natural log transform of $K\left[\mathrm{LT}^{-1}\right]$

physical clogging factor $\left[\mathrm{T}^{-1}\right.$

coefficient of proportionality between $\delta \phi / \phi$ and $\delta C / C[-]$

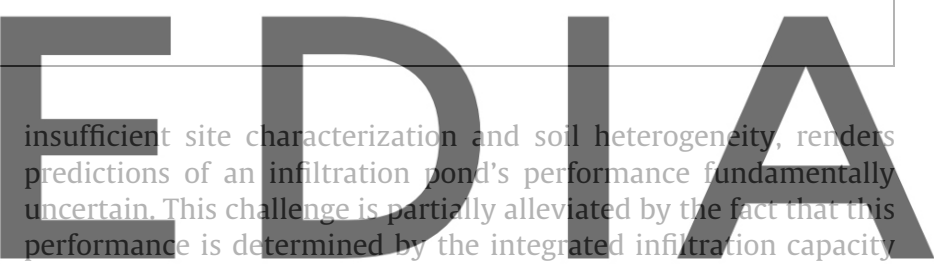

$\bar{I}(t)$ rather than the actual distribution of local infiltration values $I(\mathbf{x}, t)$.

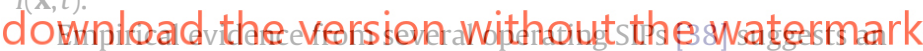 exponential decay behavior in the overall infiltration capacity,}

$\bar{I}(t)=\bar{I}_{0} \mathrm{e}^{-\lambda_{\mathrm{eff}} t}$

where the initial capacity $\bar{I}_{0}$ and the effective decay (clogging) rate $\lambda_{\text {eff }}$ are highly uncertain fitting parameters that are difficult to predict prior to the SIP's operation. Actually, in general, the infiltration rate tends asymptotically to a non-zero value [37], but is most cases this asymptotic value is very small compared to the initial one and can thus be approximate by a zero value.

A variety of maintenance activities with different scheduling plans can be applied to SIPs to control the reduction of $\bar{I}(t)$ with time $[10,39]$. These can be subdivided into preventive or corrective measures [8]. Preventive or maintenance activities are performed during the operation period in order to extend the system's life. Examples include pre-filtering input water to eliminate particles, scraping the soil surface before infiltration, using disinfectants to control algal growth, designing a large settling pond to remove organic matter, and controlling entry water temperature to avoid gas bubbling. Corrective measures must be taken if and when $\bar{I}(t)$ reaches its minimally acceptable level $I_{c}$. For these the operation of the SIP must be temporarily stopped. Examples include scraping the bottom surface when the basins are dried out after specific recharge cycles, supplying additional disinfectants or chemicals to the water, or using underwater robots to scrape the soil surface during infiltration.

Regardless of the maintenance strategy, a SIP's operating life is highly uncertain. Maintenance decisions have to be made under uncertainty, calling for a probabilistic approach. However, current 
practice is to schedule corrective measures based on experience and monitoring [14]. An optimal scheduling and selection of maintenance measures affects the operational costs of SIPs. Forecasting these costs is subject to uncertainty and depends on many factors, such as the optimal performance of the chemical products, the input water quality and the performance of scraping machines.

\section{Processes contributing to SIP failure}

We define a "system failure" at time $t$ as the event "water infiltration capacity $\bar{I}(t)$ falls below a design value $I_{c}$ ". Among a large number of events that can lead to system failure are interruptions in water supply to the pond, deposition of extraneous impermeable materials at the pond's bottom, bad design and/or improper use of the pond, and its complete breakdown due to embankment slides, earthquakes, and acts of vandalism [24]. These and other similar events should be included into a complete probabilistic risk assessment of SIPS, but lie outside the scope of the present analysis.

Instead, we focus on system failures due to reduction in the soil's infiltration capacity caused by clogging. A mathematical model capturing the relationship between infiltration capacity and the soil hydraulic parameters is presented in Section 3.1. Various clogging mechanisms are discussed, modeled, and combined together for an effective model of clogging in Section 3.2.

3.1. Infiltration and hydraulic parameters where $I_{0}(\mathbf{x})=I(\mathbf{x}, t=0)$ and $K_{0}(\mathbf{x})=K(\mathbf{x}, t=0)$ are the initial values of the infiltration capacity and the hydraulic conductivity, respectively. Combining (4) and (5), we obtain an equation relating the reduction in infiltration capacity to the reduction in porosity,

$\frac{I(\mathbf{x}, t)}{I_{0}(\mathbf{x})}=\frac{\phi^{3}(\mathbf{x}, t)}{\phi_{0}^{3}(\mathbf{x})} \frac{\left[1-\phi_{0}(\mathbf{x})\right]^{2}}{[1-\phi(\mathbf{x})]^{2}} \approx \frac{\phi^{3}(\mathbf{x}, t)}{\phi_{0}^{3}(\mathbf{x})}$,

where $\phi_{0}(\mathbf{x})=\phi(\mathbf{x}, t=0)$ is the initial porosity before clogging started to occur. The approximation in (6) is valid as long as temporal changes in $\phi$ remain small.

\subsection{Mathematical models of clogging}

A number of physical [52], biological [7,21] and chemical [29] processes can contribute to clogging. Their complex interplay complicates the development of fully comprehensive mathematical models of clogging even though individual mechanisms are relatively well understood $[16,19,20,46]$. Representative models of the three clogging mechanisms are discussed below.

\subsubsection{Physical clogging}

Physical clogging typically refers to filtration processes that reduce porosity $\phi$ through sedimentation and dragging of suspended particles [31,52]. Following [31], we employ a first-order mass transfer model,

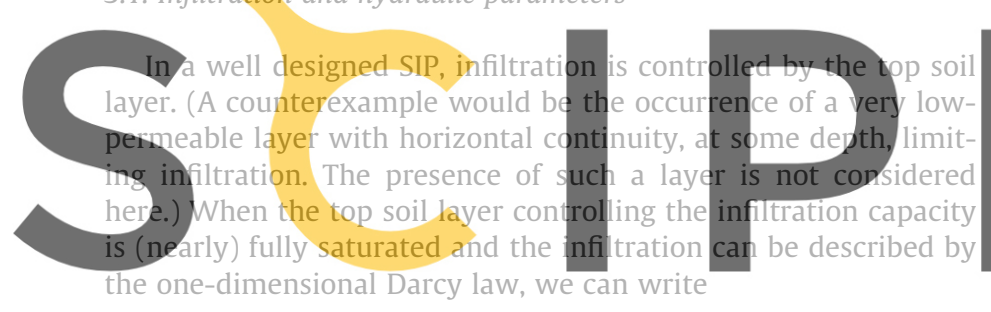

Register for friee a afzttps//www.scipedia.com to

where $\mathbf{x}=(x, y)^{T}$ is the vector of horizontal coordinates, $z$ is the vertical coordinate, $h$ is the hydraulic head, and $K$ is the saturated vertical hydraulic conductivity. The latter is defined as $K=\kappa \rho_{w} g / \mu_{w}$, where $\kappa$ is the soil intrinsic permeability in the vertical direction, $\rho_{w}$ and $\mu_{w}$ are the density and dynamic viscosity of water, respectively; and $g$ is the gravity acceleration constant.

To account for changes in hydraulic conductivity due to pore clogging, we adopt the Kozeny-Carman law [32,13] according to which permeability $\kappa$ varies with the soil porosity $\phi$ as

$\kappa=\frac{d_{m}}{180} \frac{\phi^{3}}{(1-\phi)^{2}}$,

where $d_{m}$ is the percentile of the cumulative distribution of the soil grain sizes.

The Kozeny-Carman law is applicable within a range of $\phi$ that includes soil grains coarser than fine sands. Such soils are typical for artificial recharge facilities, which typically are built in (highly permeable) coarse sandy sedimentary environments. However it is important to note that the Kozeny-Carman law is known to suffer from severe limitations that the user should be aware of prior to application (e.g. [15]). When such limitations occur, alternative models can be integrated into this framework.

Assuming that the water properties and hydraulic gradient do not change over time, it follows from (3) that any reduction in infiltration capacity is linearly related to the reduction in $K$, i.e.,

$\frac{I(\mathbf{x}, t)}{I_{0}(\mathbf{x})}=\frac{K(\mathbf{x}, t)}{K_{0}(\mathbf{x})}$

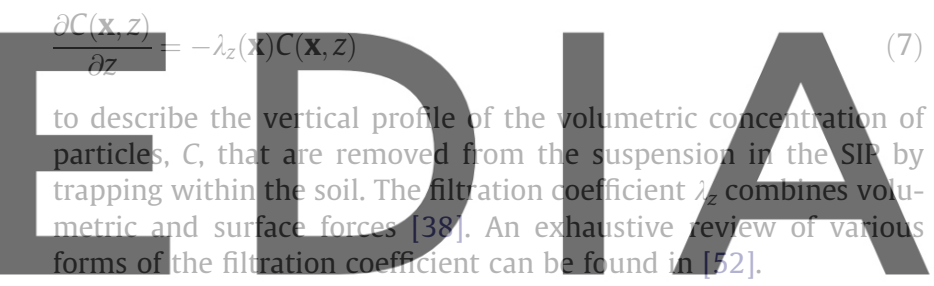

In a typical model, e.g., [11], $\lambda_{z}$ is a combination of the following mechanisms:

ownload the version without the watermark

- filtration induced by inertial forces, $\lambda_{\text {ine }} \propto d_{s}^{1.5}$

- filtration due to interception mechanisms, $\lambda_{\text {int }}=\left(d_{s} / d_{g}\right)^{n} / d_{g}$;

- filtration caused by molecular (van der Waals) forces, $\lambda_{\text {mol }} \propto d_{s}^{2}$;

- filtration due to diffusion, $\lambda_{\text {dif }}=\left[\phi_{0} K_{b} T /\left(\mu_{w} d_{s} d_{g}|\mathbf{q}|\right)\right]^{0.66} / d_{g}$;

- filtration due to sedimentation, $\lambda_{\text {sed }}=g \phi_{0}\left(\rho_{k}-\rho_{w}\right) d_{s}^{2} /\left(18 \mu_{w}\right.$ $\left.d_{g}|\mathbf{q}|\right)$.

$d_{s}$ is the mean diameter of suspended particles in the water during the flooding stage, $d_{g}$ is the characteristic grain size of the soil, $n$ is the geometrical parameter for clogging interception mechanisms, $K_{b}$ is the Boltzmann constant, $T$ is the water temperature, $\mathbf{q}$ is the flow velocity of water, and $\rho_{k}$ is the bulk density of the soil.

Empirical relationships can be used to relate the characteristic grain size $d_{g}$ to the soil permeability $\kappa$. In the present analysis, we choose the Hazen formula [30],

$\kappa=A d_{10}^{2}, \quad A \approx 100$

in which $d_{g}=d_{10}$, the grain size corresponding to the tenth percentile in the cumulative distribution of grain sizes. The Hazen formula (8) is most appropriate for clean sands, which are typical in SIPs. It is worth emphasizing that the Hazen formula is used here for illustrative purposes, and can be replaced by other textural relations. Finally, we assume that $d_{10}$ remains constant during an SIP's operation, i.e., that the clogging material does not change the grain size distribution over time. This is deemed reasonable as clogging materials are typically an order of magnitude smaller (in the case of suspended particle) or have lower density (in the case of biomass) than the original material. 
Let $v_{a}$ denote an average particle attachment velocity to the soil matrix. Typical values of $v_{a}$ can be obtained from the literature or from laboratory experiments. The experiments reported in [38] yield $v_{a} \approx 10^{-5} \mathrm{~m} /$ day, which is in agreement with reference values suggested in [45]. Setting $t=z / v_{a}$ in (7) and integrating in time yields

$C(\mathbf{x}, t)=C_{0}(\mathbf{x}) \mathrm{e}^{-\lambda_{p}^{*}(\mathbf{x}) t}, \quad \lambda_{p}^{*}=\lambda_{z} v_{a}$,

where $C_{0}(\mathbf{x})$ is the initial concentration of particles in the soil column. Changes in the particle concentration, $\delta C$, cause changes in the porosity, $\delta \phi$. We postulate a linear relation between the two, $\delta \phi / \phi=m_{p} \delta C / C$, where $m_{p}$ is the coefficient of proportionality. It follows from (9) that

$\phi(\mathbf{x}, t)=\phi_{0}(\mathbf{x}) \mathrm{e}^{-\lambda_{p}(\mathbf{x}) t}, \quad \lambda_{p}=m_{p} \lambda_{p}^{*}$,

where $\lambda_{p}$ can be seen as the characteristic physical clogging factor. Substituting (10) into (6) yields a model describing the exponential reduction in the infiltration capacity due to physical clogging,

$I(\mathbf{x}, t)=I_{0}(\mathbf{x}) \mathrm{e}^{-3 \lambda_{p}(\mathbf{x}) t}$.

\subsubsection{Biological clogging}

Biological activity, such as biomass growth and biogas generation, obstructs the pores and reduces both porosity and pore connectivity [7]. Biological clogging is typically described with one of the three approaches: macroscopic models, micro-colony-based models, and biofilm-based models. Macroscopic transport equations resulting from all three are identical i are fully penetrating [6]. Furthermore, th acceptable predictions for coarse-textur typical ip SIP operations), while pod textured materials [49].

Bio-clogging manifests itself through a combination of factors: formation of a thin impermeable layer at the soll surface, biofilm formation on the soil grains, and precipitation of biomass that oc-

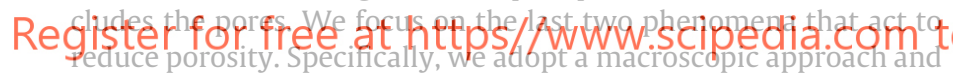
assume that all biomass growth leads to a direct reduction of porosity, $\phi(\mathbf{x}, t)=\phi_{0}(\mathbf{x})-\phi_{b}(\mathbf{x}, t)$, so that

$\frac{\phi(\mathbf{x}, t)}{\phi_{0}(\mathbf{x})}=1-\frac{\phi_{b}(\mathbf{x}, t)}{\phi_{0}(\mathbf{x})}$.

The fraction of the pore volume occupied by the biological mass, $\phi_{b}(\mathbf{x}, t)$, can be expressed in terms of $M_{b}$, the relative biomass attached to the soil, and the biomass density $\rho_{b}$, [21], such that

$\phi_{b}(\mathbf{x}, t)=\frac{\rho_{k}(\mathbf{x})}{\rho_{b}} M_{b}(\mathbf{x}, t)$.

In general, biomass growth occurs in four stages: time-lag (adaptation), exponential growth (microbes have acclimated), stationary (limiting substrate), and decay (substrate exhausted) [54]. While assessing the performance of SIPs, one is concerned with the initial stages of bio-clogging in which biomass grows exponentially,

$M_{b}(\mathbf{x})=M_{b}^{*}(\mathbf{x})\left[\mathrm{e}^{\lambda_{s}(\mathbf{x}) t}-1\right]$,

where $M_{b}^{*}(\mathbf{x})$ is the initial distribution of biomass and $\lambda_{s}(\mathbf{x})$ is the microbial growth parameter. Combining (12)-(14) yields

$\frac{\phi(\mathbf{x}, t)}{\phi_{0}(\mathbf{x})}=1-\frac{\rho_{k}(\mathbf{x}) M_{b}^{*}(\mathbf{x})}{\rho_{b} \phi_{0}(\mathbf{x})}\left[\mathrm{e}^{\lambda_{s}(\mathbf{x}) t}-1\right]$.

For $\lambda_{s} t \ll 1$, (15) can be approximated by

$\frac{\phi}{\phi_{0}} \approx 1-\frac{\rho_{k} M_{b}^{*} \lambda_{s}}{\rho_{b} \phi_{0}} t \approx \mathrm{e}^{-\lambda_{b}(\mathbf{x}) t}, \quad \lambda_{b}=\frac{\rho_{k} M_{b}^{*} \lambda_{s}}{\rho_{b} \phi_{0}}$.
This approximation implicitly assumes the variation in porosity due to biofilm growth to be small relative to the initial biomass. It is adequate for risk assessment purposes, since a large reduction in porosity and permeability would make the SIP operation not viable. In other words, standard SIP operations would not allow clogging to develop beyond the exponential growth phase.

Substituting (16) into (6) yields a model describing the exponential reduction in the infiltration capacity due to biological clogging,

$I(\mathbf{x}, t)=I_{0}(\mathbf{x}) \mathrm{e}^{-3 \lambda_{b}(\mathbf{x}) t}$.

\subsubsection{Chemical clogging}

During the initial filling of a pond, gas can be generated within pores by a number of chemical processes, including microorganism activity, temperature effects, and the release of trapped bubbles $[17,27]$. As the air continues to occupy some pores (mainly large ones), water saturation and consequently hydraulic conductivity and infiltration rates decrease. Degassing can be rapidly reversed if the proper water temperature conditions are met [38]. The relationship between moisture content and conductivity is also characteristic of the grain size (i.e. type of soil); when this is similar to the pore distribution, the heterogeneous distribution of gas clogging factors would also show a spatial variability similar to the one of the grain size. However, direct measurements of the characteristic curves are challenging and costly. We take advantage of the fact that clogging due to gas formation takes place at small time scales (much smaller than those associated with physica) and bio-
logical clogging). This allows as to employ an instantaneous reduc-
tion model of gas clogging,
$I(\mathbf{X}, t)=R(\mathbf{x}) I_{0}(\mathbf{x})$,
where the reduction factor $R(\mathbf{x}) \in(0,1]$ is treated as an uncertain
(random) fitting parameter.

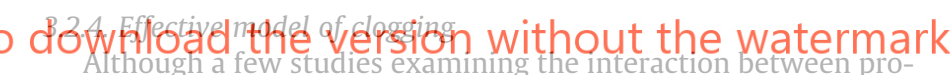
cesses exist (e.g. [26,40,3] for physical and biological clogging), most scarcely provide quantitative information about the cumulative effect on reducing the infiltration capacity. For modeling purposes, we obtain the overall reduction in the infiltration capacity by linearly combining (11), (17) and (18), such that

$I(\mathbf{x}, t)=R(\mathbf{x}) I_{0}(\mathbf{x}) \mathrm{e}^{-3\left[\lambda_{p}(\mathbf{x})+\lambda_{b}(\mathbf{x})\right] t}$.

\section{Dependence of SIP Performance on Soil Parameters}

Predictions of clogging and the corresponding reduction in infiltration capacity depend on a number of parameters, whose values are highly uncertain due to soil heterogeneity. We adopt a probabilistic framework both to predict the effects of clogging on a SIP's infiltration capacity and to quantify the predictive uncertainty.

Specifically, we focus on the impact of soil texture, as incapsulated by the grain size parameter $d_{g}$, on the reduction in the SIP infiltration capacity due to various clogging mechanisms. Recall that $d_{g}$ can be directly related to the initial infiltration values $I_{0}$ using (3) and (8), so that we could alternatively have selected $I_{0}(\mathbf{x})$ or $K_{0}(\mathbf{x})$. In Section 3, we demonstrated how the reduction in the infiltration capacity $I(\mathbf{x}, t)$ in (19) can be related to the soil texture and to the soil particle size $d_{g}$. The following sensitivity analysis is used to explore further the question of how this soil parameter affects various clogging mechanisms and, via (19), the SIP infiltration capacity.

The following grain sizes and soil densities were chosen to represent three different types of soils: 
Table 1

Selected values for model entry parameters used for sensitivity analysis.

\begin{tabular}{lll}
\hline Parameter & Value & Unit \\
\hline$d_{s}$ & $2 \times 10^{-3}$ & $\mathrm{~cm}$ \\
$\rho_{s}$ & 1.5 & $\mathrm{~g} / \mathrm{cm}^{3}$ \\
$n$ & 2 & - \\
$T$ & 298 & $\mathrm{~K}$ \\
$\rho_{w}$ & 1 & $\mathrm{~g} / \mathrm{cm}^{3}$ \\
$\mu_{w}$ & $1.002 \times 10^{-7}$ & $\mathrm{~N} \times \mathrm{s} / \mathrm{cm}^{2}$ \\
$\rho_{b}$ & $2.5 \times 10^{-3}$ & $\mathrm{~g} / \mathrm{cm}^{3}$ \\
$\lambda_{s}$ & $2.5 \times 10^{-3}$ & $1 / \mathrm{day}$ \\
$\phi_{0}$ & 0.3 & - \\
$|\mathbf{q}|$ & 0.1 & $\mathrm{~m} /$ day \\
\hline
\end{tabular}

- $d_{g}=1.5 \times 10^{-2} \mathrm{~cm}$ and $\rho_{k}=1.8 \mathrm{~g} / \mathrm{cm}^{3}$ for soils of type (a),

- $d_{g}=1.5 \times 10^{-3} \mathrm{~cm}$ and $\rho_{k}=1.5 \mathrm{~g} / \mathrm{cm}^{3}$ for soils of type (b),

- $d_{g}=1.5 \times 10^{-4} \mathrm{~cm}$ and $\rho_{k}=1.2 \mathrm{~g} / \mathrm{cm}^{3}$ for soils of type (c).

The other parameters used for these simulations are reported in Table 1 , taken as typical values encountered in the literature cited within this work. Note that the use of $\lambda_{s}=2.5 \times 10^{-3} 1 /$ day renders the approximation (16) applicable for $t$ on the order of hundreds of days. Finally, we fix $\phi_{0}=0.3$ and $|\mathbf{q}|=0.1 \mathrm{~m} /$ day even though these parameters are expected to vary with $d_{\mathrm{g}}$. This is done to isolate the relative importance of the physical and biological clogging, both of which depend exclusively on the grain size $d_{g}$.

Fig. 1 illustrates the temporal evolution of the infiltration capacities, normalized by the corresponding initial values, considering

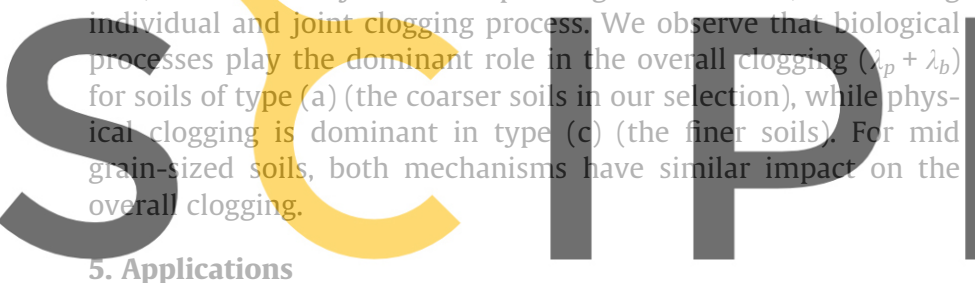

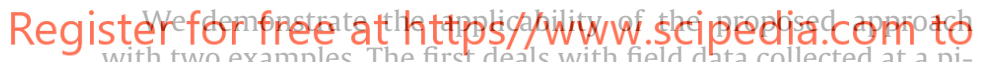
lot SIP site (Section 5.1). The second considers several synthetic examples that enable one to analyze the approach accuracy and robustness, and to quantify predictive uncertainty (Section 5.2).

\subsection{Pilot SIP in Sant Vicenç dels Horts, Spain}

We use the mathematical framework developed in Sections 3 and 4 to predict soil clogging and the corresponding reduction in

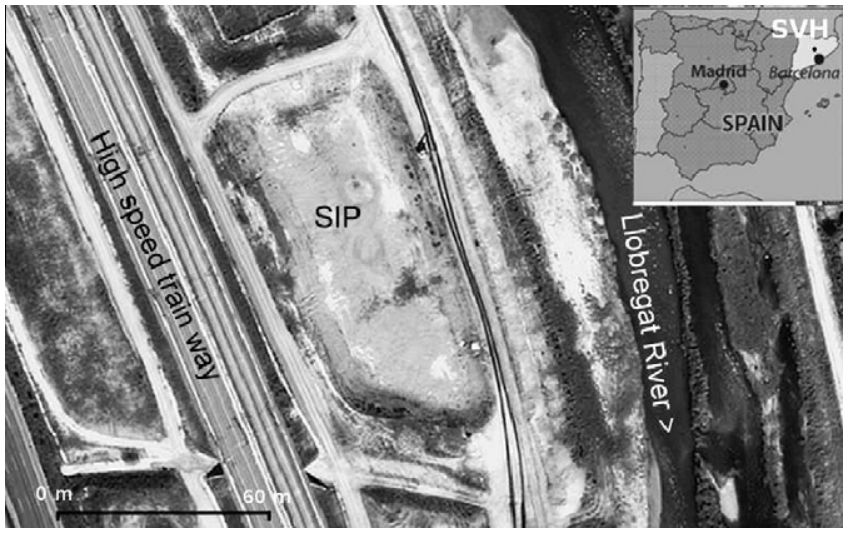

Fig. 2. A satellite image of the surface infiltration pond (SIP) in Sant Vicenç dels Horts (SVH), near Barcelona (Spain). The image corresponds to pre-infiltration conditions (November, 2007).

the pond's infiltration capacity at a SIP site located in Sant Vicenç dels Horts (herein, SVH) near the city of Barcelona, Spain. The site (Fig. 2) lies in the prodelta region of the Llobregat river, whose geology is a sequence of fine- and coarse-grained facies of silicoclastic materials, deposited according to the evolution of the paleo-river. The hydrogeological setting consists of sandy-gravel or

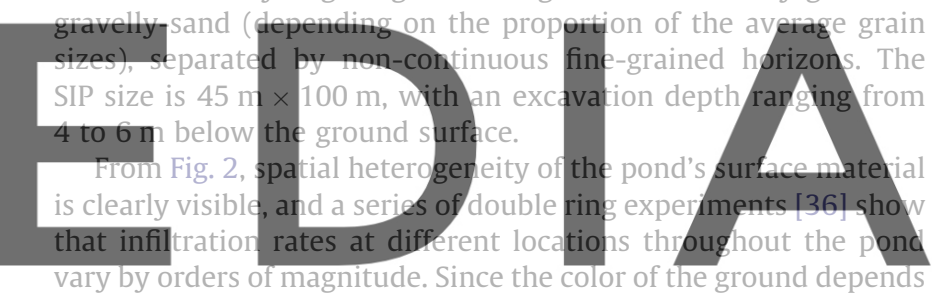

closely on the soil texture, which in turn is correlated with the

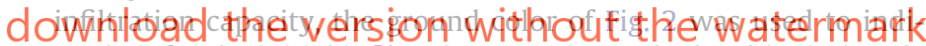
rectly infer the initial infiltration capacity at the local (point) scale $I_{0}(\mathbf{x})$ throughout the pond (Fig. 3A) [36]. The authors found the local measured infiltration rates to be linearly correlated with the logarithm of the pixel intensity of the satellite image in Fig. 2 (which happened to have approximately the same measurement support, on the order of $\mathrm{dm}^{2}$ ). The data analysis in [36] provides a rare example of SIPs, in which the initial local infiltration capacities are known with sufficient certainty. In general, this is not the case, and uncertainty (randomness) in $I_{0}(\mathbf{x})$ should be accounted (a) Coarse soils

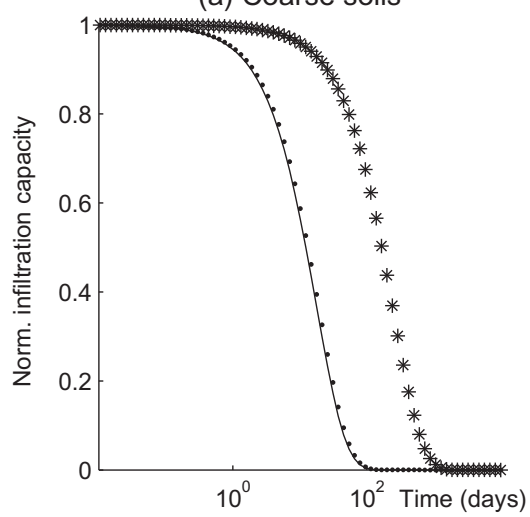

(b) Mid soils

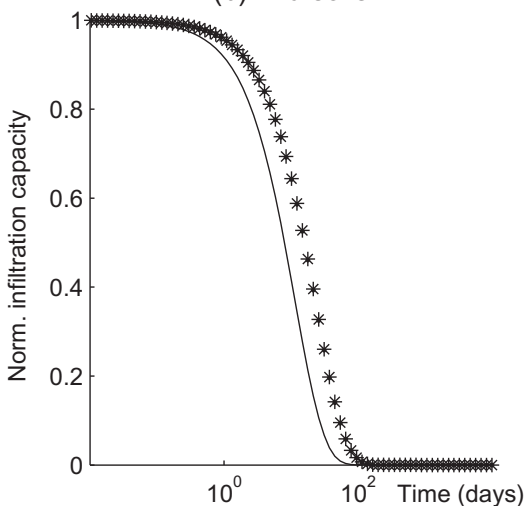

(c) Fine soils

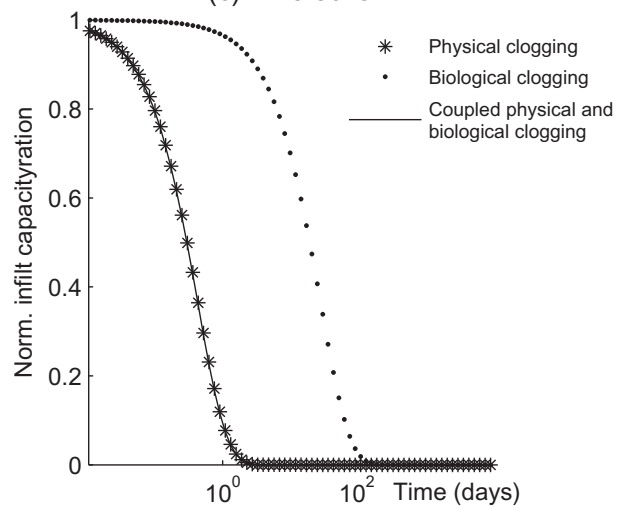

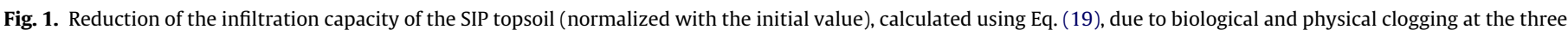

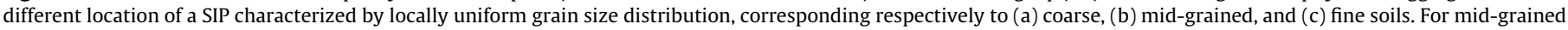
soils, physical clogging (stars) and biological clogging (points) practically overlap. 
(a)

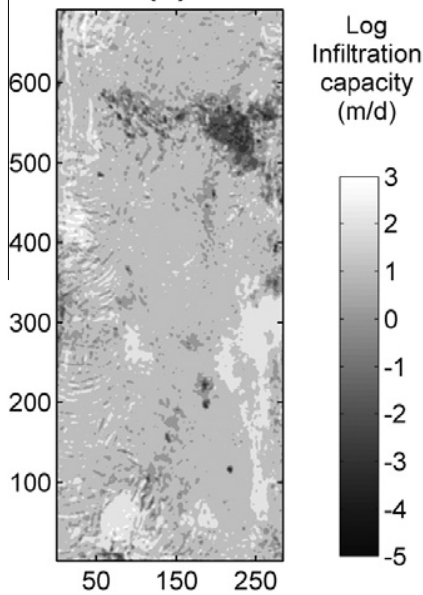

(b)

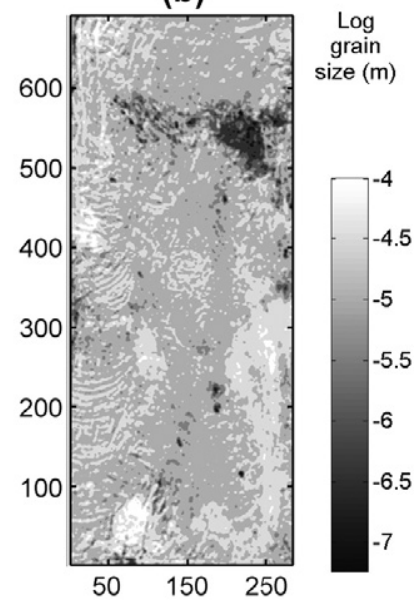

Fig. 3. (A) Reference map of initial infiltration capacity distribution (modified from [36]), and (B) relative grain-size distribution predicted with the Hazen formula (8). The size of the image is $286 \times 694$ pixels. Coordinates are also in pixels.

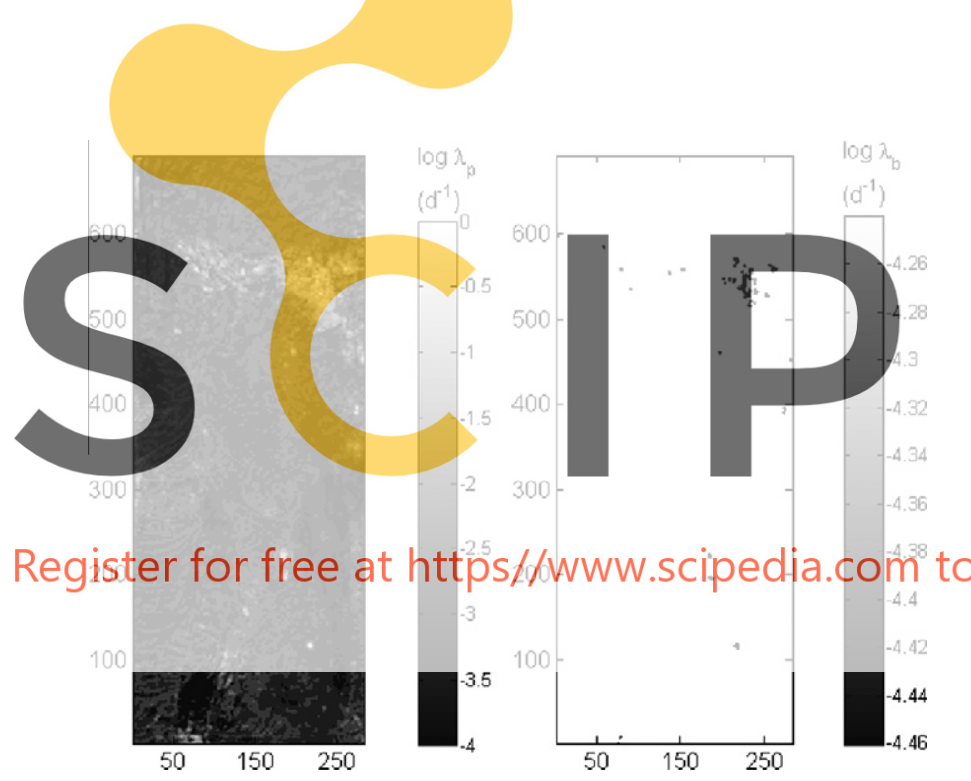

Fig. 4. Spatial distributions of (A) the physical clogging rates $\lambda_{p}$ and (B) the biological clogging rates $\lambda_{b}$, inferred from the spatial distribution of $d_{g}$ in the reference domain. As such, each value has a pixel-size support volume. Notice scales are different in both plots.

for in decision-making. In the analysis below, we explore both scenarios.

In this work we use Fig. $3 \mathrm{~A}$ as our reference raster of initial infiltration capacities $\left(I_{0}(\mathbf{x})\right)$. The map is a rectangular domain of $286 \times 694$ pixels, which was obtained by sampling and transforming the central domain of Fig. 2 . This geometry allows us to apply the method described in [36] (the careful reader will note that the image here is a mirror version of the one use by these authors).

Fig. 3B exhibits the characteristic grain size distribution $d_{g}(\mathbf{x})$ inferred from the distribution of $I_{0}(\mathbf{x})$ in Fig. 3A by means of the Hazen formula (8). The logarithmic color scales in Fig. 3 highlight the high degree of spatial variability of the parameters considered in this study at the local (i.e., pixel) scale $\left(\approx 10^{2} \mathrm{~cm}^{2}\right)$. The parameters are inferred, and assumed to be constant, on a pixel basis.

The estimates of the grain-size distribution $d_{g}(\mathbf{x})$ in Fig. 3B rely on the relationship between the pixel intensity and the infiltration rate and on the Hazen formula (8), both of which are likely to introduce estimation errors. The impact of uncertainty on predictions of the SIP infiltration capacity is quantified in Section 5.2 by conducting a series of Monte Carlo simulations. In the remainder of this subsection, we treat the grain-size distribution $d_{g}(\mathbf{x})$ in Fig. 3B deterministically, i.e., as a realization of the corresponding random field.

Fig. 4 shows the estimates of physical clogging rates $\lambda_{p}(\mathbf{x})$ (Fig. 4A) and biological clogging rates $\lambda_{b}(\mathbf{x})$ (Fig. 4B) obtained from the estimates of the characteristic grain sizes $d_{g}(\mathbf{x})$ by following the procedure described in Sections 3.2.1 and 3.2.2. Note that the values of $\lambda_{p}$ span four orders of magnitude, while $\lambda_{b}$ is relatively uniform. In these calculations, we adopt the same default values for entry parameters as in Table $1 . \rho_{k}$ was related to $d_{g}$ according to the relationship established in Section 4.

To simplify the presentation, we take the reduction factor $R$ due to gas clogging to be spatially homogeneous and set it to $R=0.9$. Spatially-varying $R(\mathbf{x})$ can be obtained by invoking physical models combined with field measurements. Substituting $\lambda_{p}(\mathbf{x})$ and $\lambda_{b}(\mathbf{x})$ from Fig. 4 into (19), we compute the infiltration capacity $I(\mathbf{x}, t)$ in each pixel. Temporal snapshots of the resulting $I(\mathbf{x}, t)$ after $t=7,14$ and 42 days of infiltration are shown in Fig. 5. A comparison of these snapshots with the initial infiltration capacity in Fig. 3A reveals a significant deterioration in performance of the SIP. While a large fraction of the SIP maintains s high infiltration capacity after 7 days, 42 days of SIP operation results in a large reduction of the area corresponding to high infiltration.

Fig. 6 summarizes the spatial variability of the infiltration capacity $I(\mathbf{x}, t)$ in Fig. $3 \mathrm{~A}$ and Fig. 5 in the form of its probability

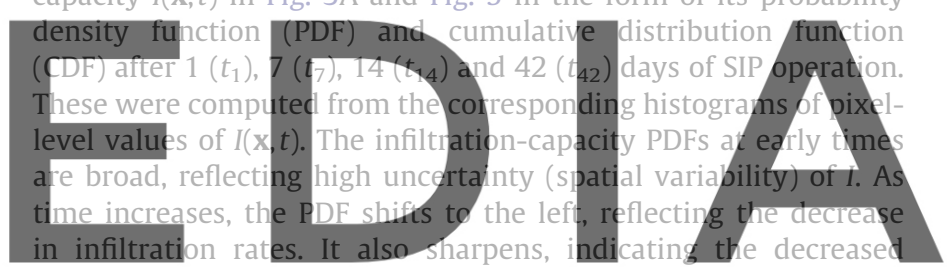

uncertainty. At all times, the PDF curves display asymmetric tailing (positively skewed curves).

\section{download the version without the watermark}

\subsubsection{On the use of effective clogging rates}

Since previous observation show that large scale flooding experiments typically display an exponential decay in infiltration rate, we explore the feasibility of using an effective clogging rate $\lambda_{\text {eff }}$ as a parameter to represent the various biological and physical clogging mechanisms over the whole SIP footprint.

We compute the mean infiltration capacity $\bar{I}(t)$ by averaging the values of $I(\mathbf{x}, t)$ in (19) over all pixels. The resulting $\bar{I}(t)$, normalized with the average initial infiltration capacity $\bar{I}_{0}$, is shown in Fig. 7a. Using a least-squares regression, the best fit exponential curve approximating the rate of change of the infiltration capacities gives a constant-in-time $\lambda_{\text {eff }} \approx 0.139 \mathrm{~d}^{-1}$, which means a characteristic clogging time of the water in the pond of 7.2 days.

Alternatively, we can estimate a variable-in-time $\lambda_{\text {eff }}(t)$ by invoking (2), such as

$\lambda_{\mathrm{eff}}(t)=-\frac{1}{t} \ln \left[\frac{\int_{\Omega} I(\mathbf{x}, t) \mathrm{d} \mathbf{x}}{\int_{\Omega} I_{0}(\mathbf{x}) \mathrm{d} \mathbf{x}}\right]$.

The results of the two methods to calculate $\lambda_{\mathrm{eff}}(t)$ are plotted together in Fig. 7b. The numerical evaluation of (20) suggests that in this case, $\lambda_{\text {eff }}$ is monotonically decreasing in time, ranging from $0.155 \mathrm{~d}^{-1}$ to $0.125 \mathrm{~d}^{-1}$ over the chosen time interval (up to 100 days). This corresponds to characteristic clogging times between 6.45 days to 8 days (Fig. $7 b$ ). From a practical perspective, this difference may be negligible and a constant effective parameter $\lambda_{\text {eff, exhibiting a "homogeneous" (or, more appropriately, homoge- }}$ nized) exponential decay, can be considered a good approximation (see the good fit in Fig. 7). 

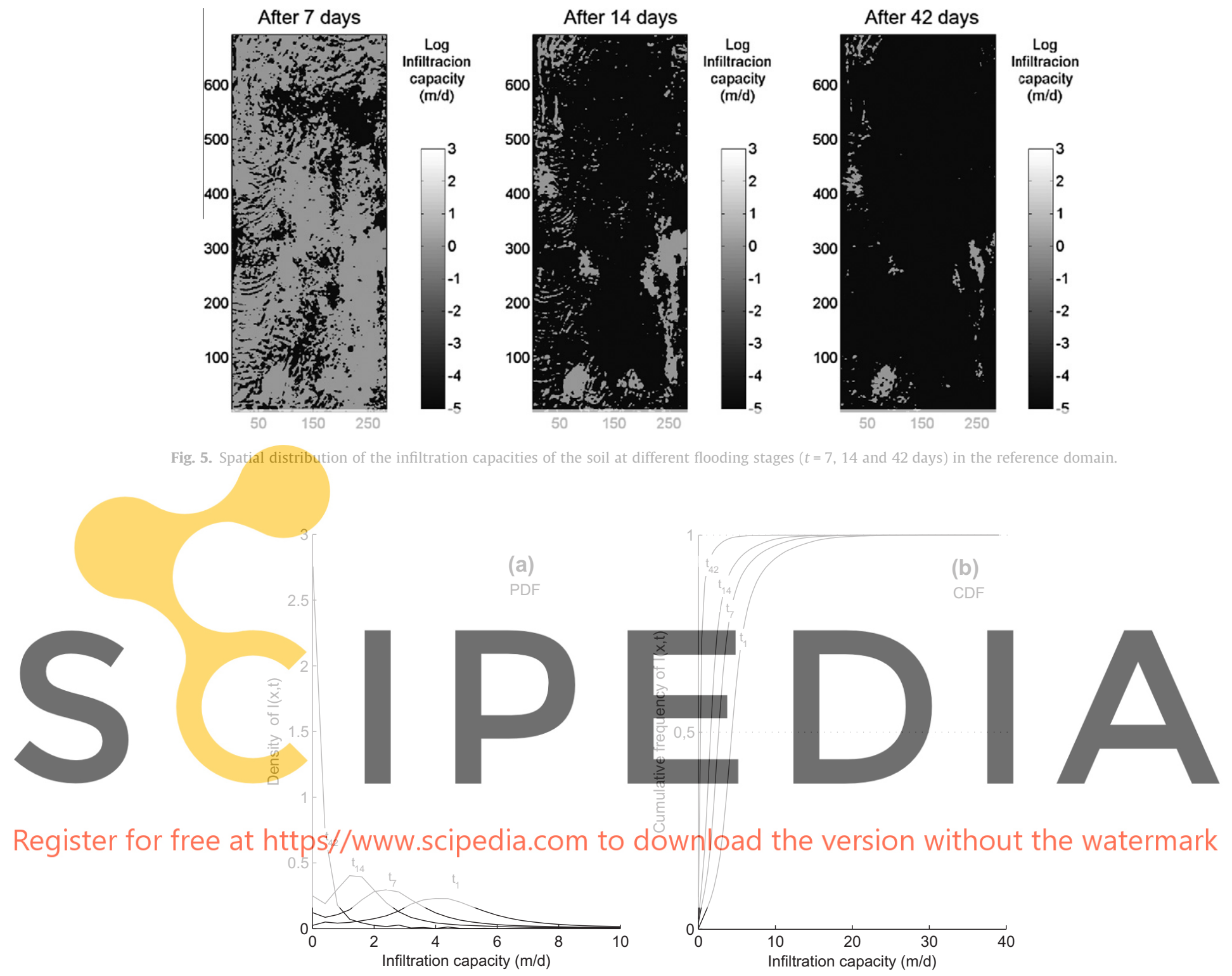

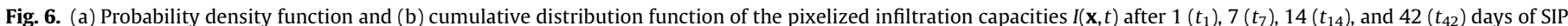
operation at the SVH site.

\subsubsection{SIP management strategies}

Next, we explore how spatial variability of the SIP infiltration capacity $I(\mathbf{x}, t)$ affects the efficiency of the following four maintenance strategies:

- No maintenance activity is performed.

- All biological clogging mechanisms are remediated (Type A).

- All physical clogging mechanisms are remediated (Type B).

- Physical clogging mechanisms are remediated in selected areas of the SIP footprint (Type C).

Type C maintenance can employ different criteria to identify the parts of the SIP footprint where the remediation is to take place. One could clean an area selected purely on geometrical criteria (e.g., target a half of the area of the pond at a time). We on the other hand pursue a Type $C$ maintenance strategy that relies on soil heterogeneity and hydraulic criteria to select clean-up areas. Specifically, we target the areas, wherein $\lambda_{p}$ in Fig. $4 \mathrm{~A}$ falls below a certain threshold value, e.g., $50 \%$ or $80 \%$ percentiles of the $\lambda_{p}$ probability distribution (Fig. 8). Since $\lambda_{p}$ is high for points displaying low $I_{0}$ and vice versa, such maintenance strategies focus on the areas with the highest initial infiltration capacity $I_{0}$. This allows one to sustain higher infiltration rates longer, thus resulting in a decrease in the reduction of the mean infiltration capacity over long time. Complex geometries over which such a maintenance is to be performed present practical implementation difficulties. Thus, this approach has little practical significance at the current stage of SIP practices but could be potentially interesting for future large scale facilities.

Fig. 9 displays the average infiltration capacity $\bar{I}(t)$ achieved with the four maintenance strategies identified above. Unsurprisingly, all the strategies increase $\bar{I}(t)$ relative to its counterpart without any maintenance. If one defines $37 \%$ of the initial infiltration rate (corresponding to a characteristic time $t=1 / \lambda_{\text {eff }}$ ) as the minimum acceptable infiltration capacity, then the SIP's operational time without maintenance is about 7 days. Treating bio-clogging extends the operational time to about 9.5 days, and the full treatment of physical clogging increases the operational time to about 28 days. This 
(a)

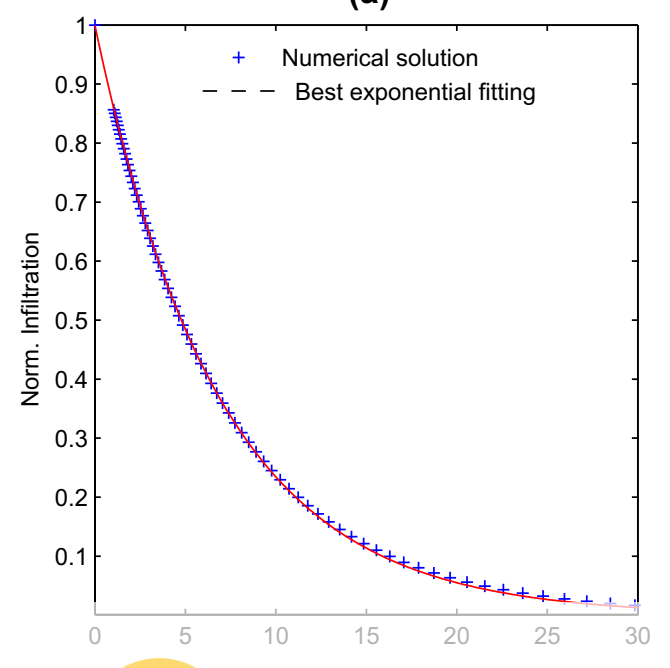

(b)

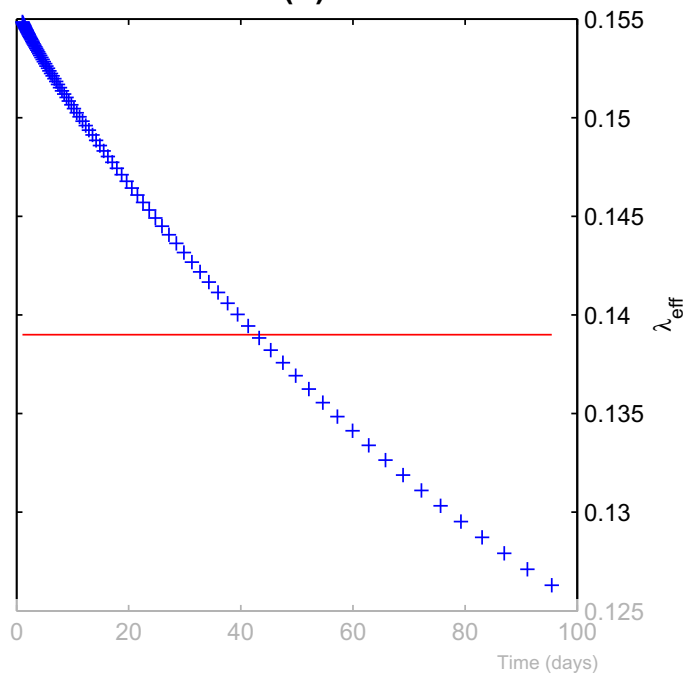

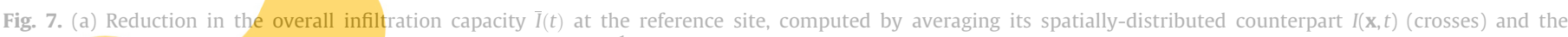

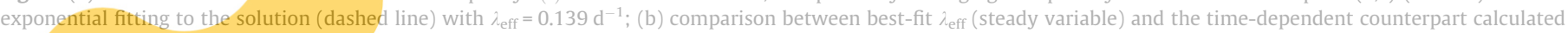
from the numerical solution (20).

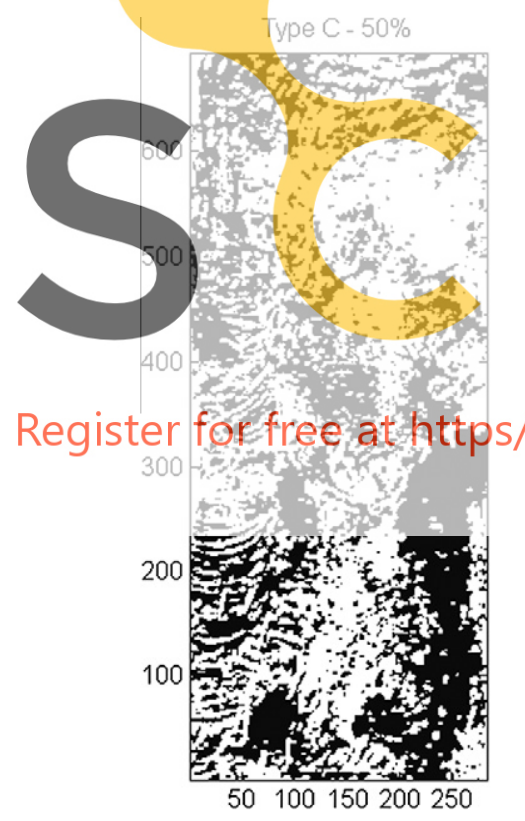

Fig. 8. Areas corresponding to the $50 \%$ (left) and $80 \%$ (right) percentiles of the initial $I_{0}$ reference distribution. These black areas should be targeted in order to minimize the impact of physical clogging rate (Type $C$ maintenance).

analysis reveals that at this site physical clogging is the primary inhibiter for maintaining effective mean infiltration rates.

If only a partial maintenance of physical clogging is performed, the treatment of $50 \%$ of the domain extends the operational time to 18-20 days. A more extensive treatment, $80 \%$ of the domain, delivers a substantial gain over the untreated case of about 25-27 days. Thus, if feasible, a partial targeted maintenance offers significant gains in operational time (and thus could be a valid cost-efficient management alternative).

\subsection{SIP operations under uncertainty}

In the preceding analysis on the pilot SIP, we assumed that all the relevant parameters to compute (19) are known with certainty.
Such a degree of certainty is uncommon in practical situations, where $d_{g}, K_{0}, I_{0}, R, \lambda_{b}$ and $\lambda_{p}$ are sparsely sampled and highly uncertain. This parametric uncertainty translates into uncertainty in pre-
dictions of whether and when the predicted mean infiltration rate
$\bar{I}(t)$ falls below a critical value c. $_{c}$.
To explore the effects of parametric uncertainty, we supplement
our analysis of the $\$ \mathrm{VH}$ site with a number of synthetic fields
whose ensemble statistics are loosely based on the data obtained
from this site. Rather than treating $d_{g}$ as our random/variable, we take the hydraulic conductivity, which we treat as deterministically linked to $d_{g}$ as random. Specifically, as is commonly done,

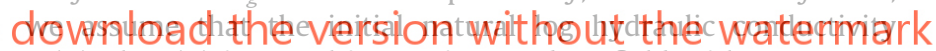
$Y_{0}(\mathbf{x})=\ln K_{0}(\mathbf{x})$ is a multi-Gaussian random field with zero mean $\overline{Y_{0}}=0$, variance $\sigma_{Y}^{2}$, an exponential variogram, and correlation length $i_{S}$. We set $h=0.5 \mathrm{~m}$ (constant in space and time) to compute $I_{0}$ from $K_{0}$ using (3) and $A=100$ to compute $d_{g}$ from $K_{0}$ using (8). Since $A$ and $h$ are constant in space and time, the spatial structure is identical for $d_{g}, K$ and $I_{0}$. Random realizations of $Y_{0}(\mathbf{x})$ were generated with the sequential simulation algorithm GSLIB [28] on a computational domain comprised of $284 \times 692$ pixels. These realizations were not conditioned to data.

Section 5.2.1 contains an analysis of the infiltration capacities $\bar{I}(t)$ for single realizations of soil parameters. Its goal is to verify the robustness and generality of our findings at the SVH site. In Section 5.2.2, we perform Monte Carlo simulations (MCS) to quantify predictive uncertainty.

\subsubsection{Analysis of individual (single) realizations}

Consider four SIPs operating in soils, whose distributions of initial infiltration capacities $I_{0}(\mathbf{x})$ are shown in Fig. 10. These fields are individual realizations of random fields obtained using different parameters, e.g. (a) $\sigma_{\mathrm{Y}}^{2}=4$ and $I_{S}=66$, (b) $\sigma_{\mathrm{Y}}^{2}=4$ and $I_{S}=6.6$, (c) $\sigma_{\mathrm{Y}}^{2}=1$ and $I_{S}=66$, and (d) $\sigma_{\mathrm{Y}}^{2}=1$ and $I_{S}=6.6$. In all cases the units for $I_{S}$ are pixels.

Fig. 11 shows how the various maintenance strategies described in Section 5.1.2 affect the decay in the normalized infiltration capacity $\bar{I}(t) / \bar{I}_{0}$ in the four synthetic fields (Fig. 10). Note here that when we say Type $\mathrm{C}$ maintenance it refers to the de-clogging of $50 \%$ of the pond surface.

For $\sigma_{\mathrm{Y}}^{2}=4$ and $I_{s}=66$, the results suggest that removal of biological clogging (Type A) yields better performance than 


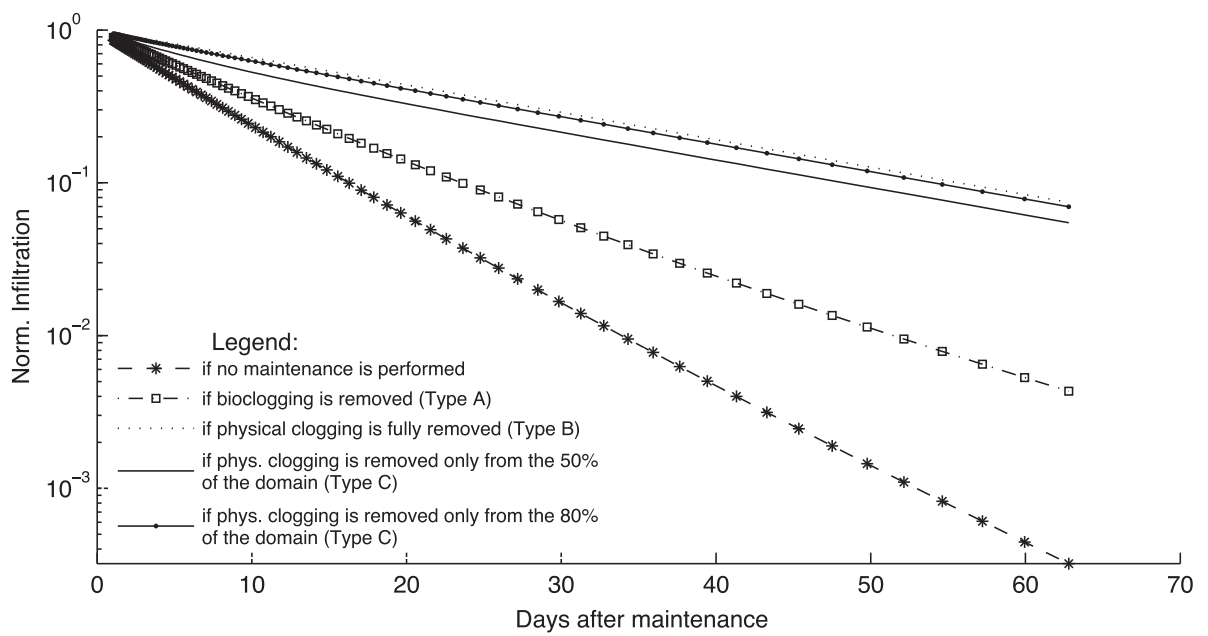

Fig. 9. Reduction in the normalized mean infiltration capacity, $\bar{I}(t) / \bar{I}_{0}$, of the reference site for the alternative maintenance strategies.

(a)

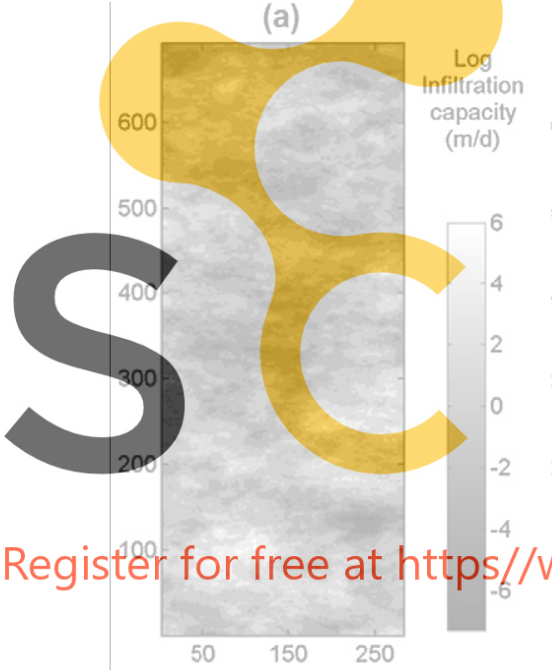

(c)

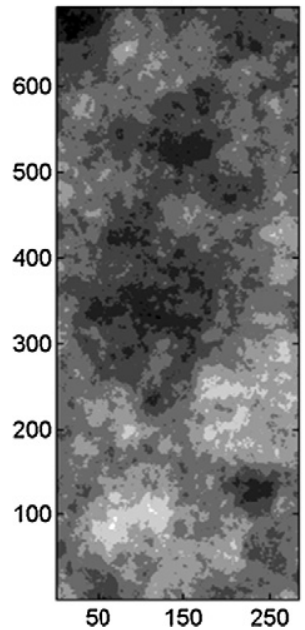

(b)

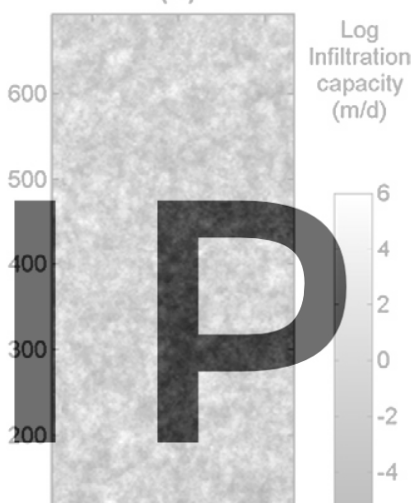

from its initial value is about $80 \%$ using Type B and C maintenance (which practically overlap in this case), while there is a reduction of around $70 \%$ with Type A. For the same variance of $\sigma_{\mathrm{Y}}^{2}=4$ but a comparatively small correlation length $\left(I_{S}=6.6\right)$, Type B and C offer slightly better performance than Type A, although after around 40-45 days of operation this behavior is inverted. However, the

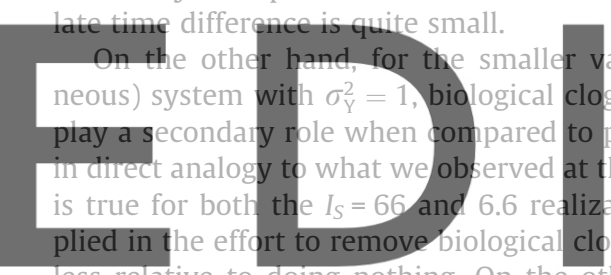

less relative to doing nothing. On the other hand both physical clogging maintenance approaches are much more effective.

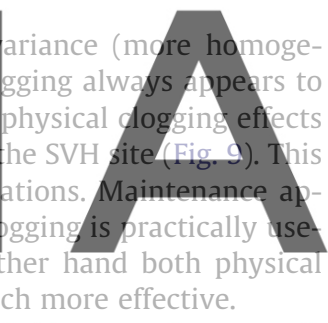

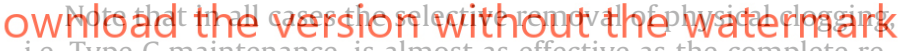
1.e. Type $\mathrm{C}$ maintenance, is almost as effective as the complete removal maintenance, particularly for the high variance cases. This is because this maintenance keeps the dominant flow channels open and the low permeability regions affect the mean value very little.

(d)

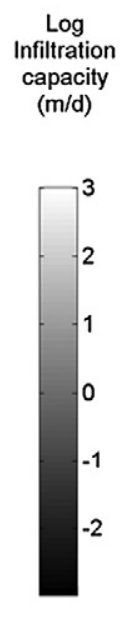

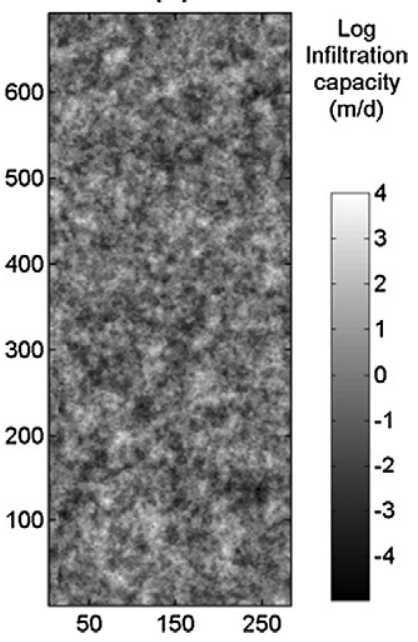

Log capacity $(\mathrm{m} / \mathrm{d})$

Fig. 10. Individual realizations of the initial infiltration capacities $I_{0}(\mathbf{x})$, using different variances of soil hydraulic conductivity $\sigma_{\mathrm{Y}}^{2}$ and correlation length $I_{S}$ : (a) $\sigma_{\mathrm{Y}}^{2}=4$ and $I_{S}=66$, (b) $\sigma_{\mathrm{Y}}^{2}=4$ and $I_{S}=6.6$, (c) $\sigma_{\mathrm{Y}}^{2}=1$ and $I_{S}=66$, and (d) $\sigma_{\mathrm{Y}}^{2}=1$ and $I_{S}=6.6$. Units of $I_{S}$ in pixels.

applications on physical processes (Types B, C). For instance, 40 days after recharge has started, the reduction of infiltration

\subsubsection{Monte Carlo analysis}

To quantify the uncertainty associated with predictions in the decline in the infiltration capacity of the four SIPs in Fig. 10, we conduct four sets of Monte Carlo simulations (MCS). Each set consists of 1000 realizations of the initial log-conductivity fields $Y_{0}(\mathbf{x})$ whose statistical properties are described in Section 5.2.1. As in the case of the single realizations, we use (3) and (8) to relate $d_{g}$ and the initial infiltration to $Y_{0}(\mathbf{x})$.

Figs. 12 and 13 display some of the most significant results of the analysis. The former displays the normalized spatially-averaged infiltration capacities against time $(\bar{I}(t))$ for each of the four statistical fields. The figure includes the ensemble mean of the predictions over all realizations, along with the degree of uncertainty for each prediction expressed by the coefficient of variation (CV). Note that apart from the case with $I_{S}=66$ and $\sigma_{\mathrm{Y}}^{2}=4$, the ensemble mean curves of Type B and C (marked by squares and circles) practically overlap.

One feature that stands out is that CV, initially zero (we assume perfect knowledge of $I_{0}$ ) increases towards larger values at different rates, that depend on the type of maintenance and geometrical distribution of soil parameters. The most uncertain cases are those with biological maintenance and with no maintenance at all, while the uncertainty is generally quite small for the system with maintenance of physical clogging. This is in some sense a reflection of the 

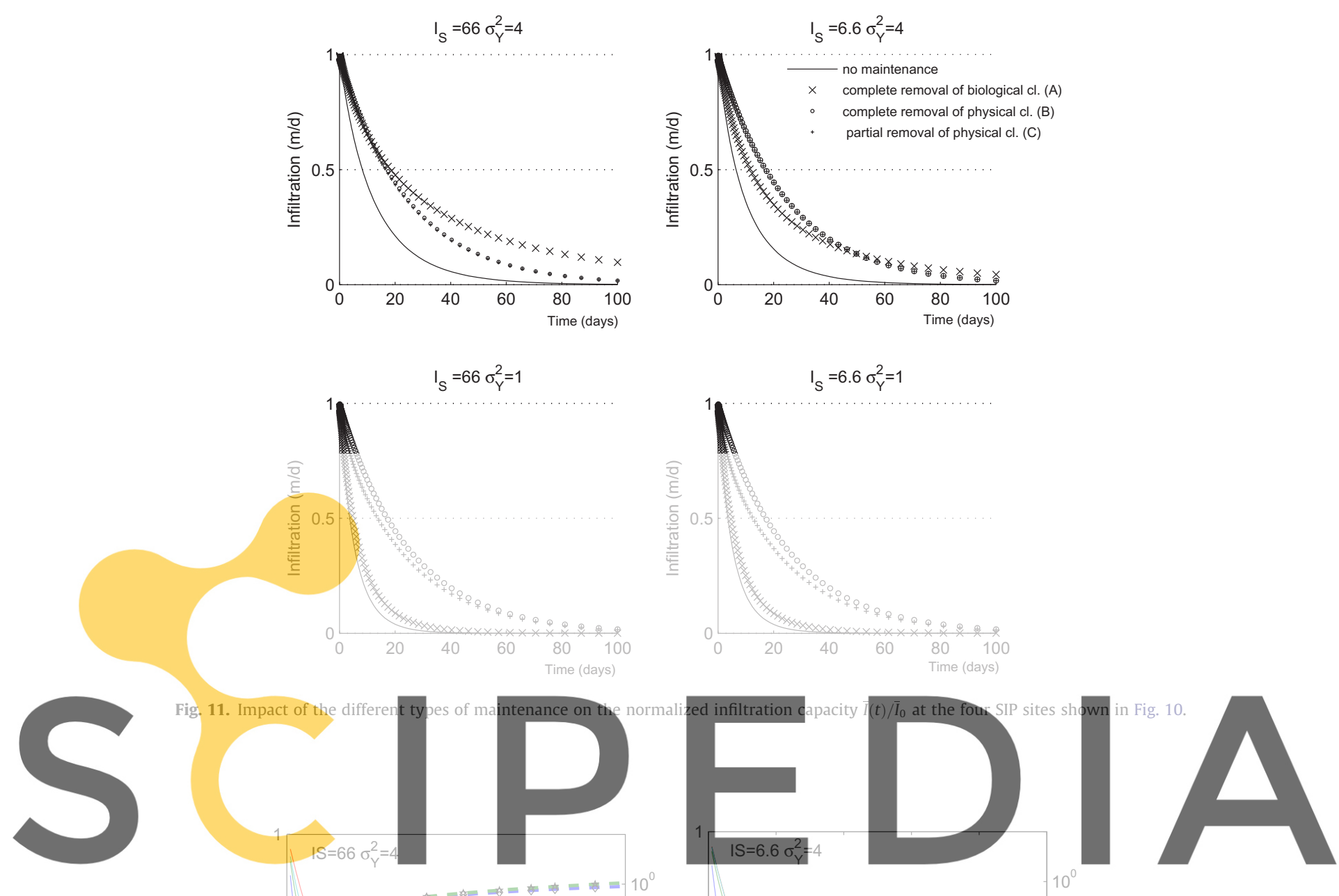

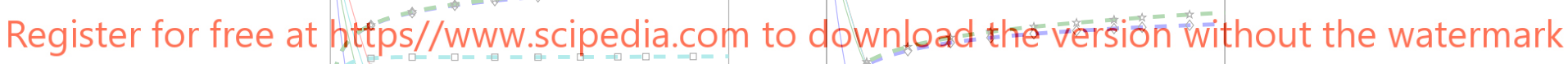

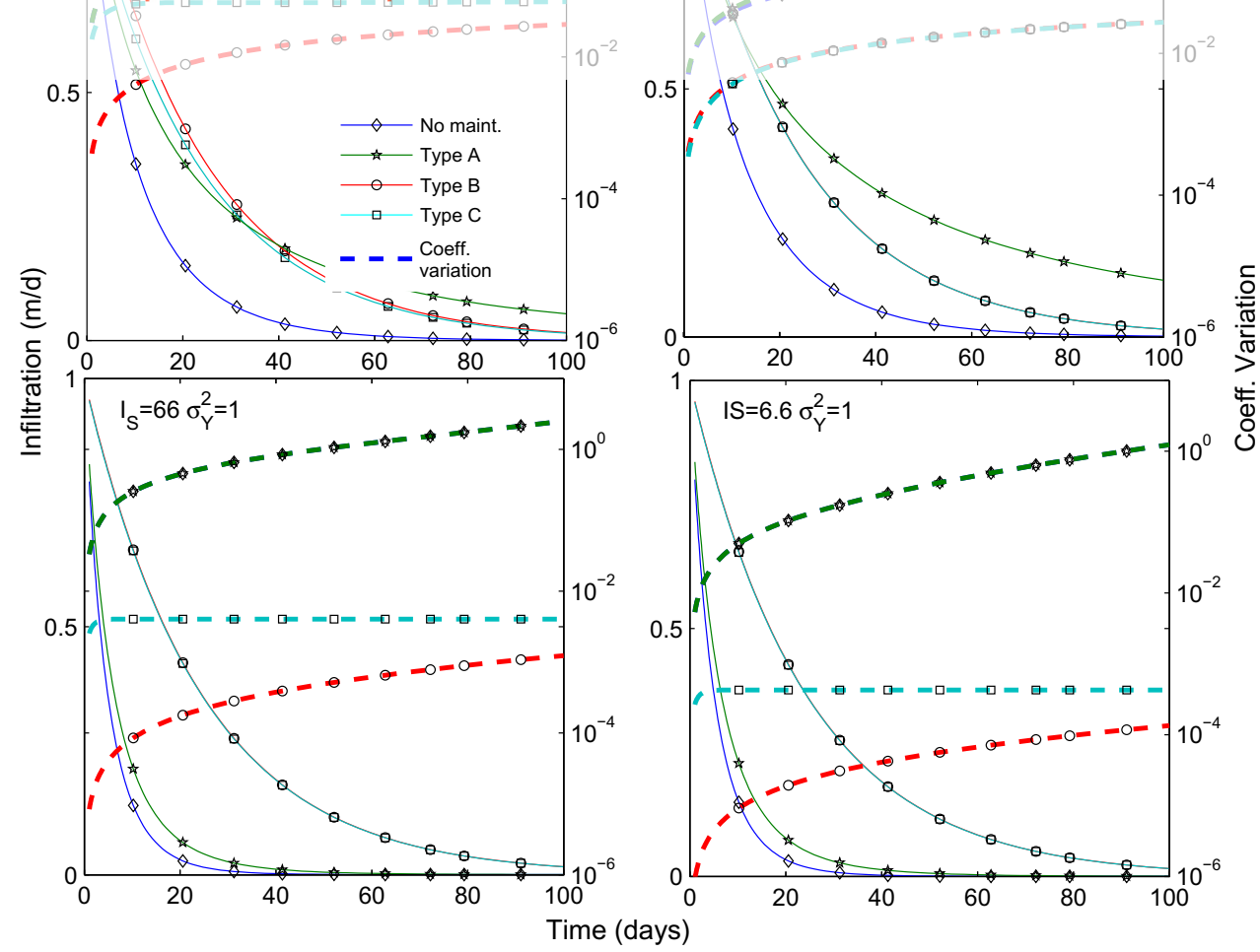

Fig. 12. Ensemble average and coefficient of variation resulting from Monte Carlo analysis (1000 realizations) of the normalized overall infiltration capacity $\bar{I}(t)$ in time for each field geometry and variance, for different types of maintenance. Notice that Type B and C curves overlap in many cases, expressing a similar behavior. 

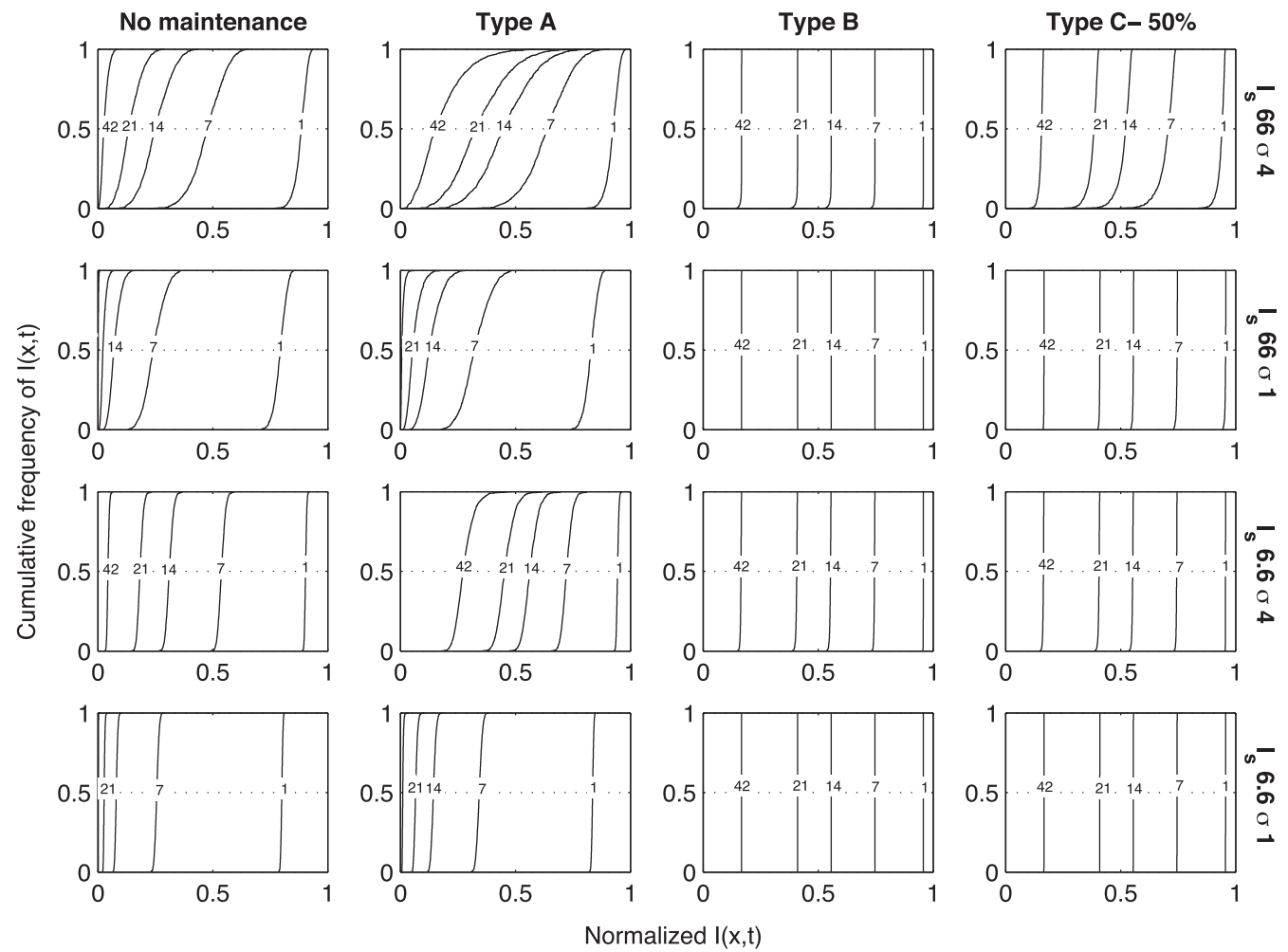

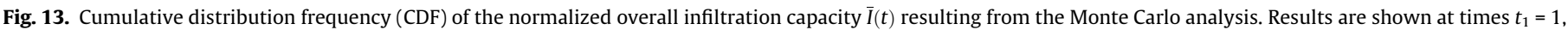
$t_{7}=7, t_{14}=14, t_{21}=21$ and $t_{42}=42$ days. Results are shown for the four synthetic fields and four maintenance strategies.
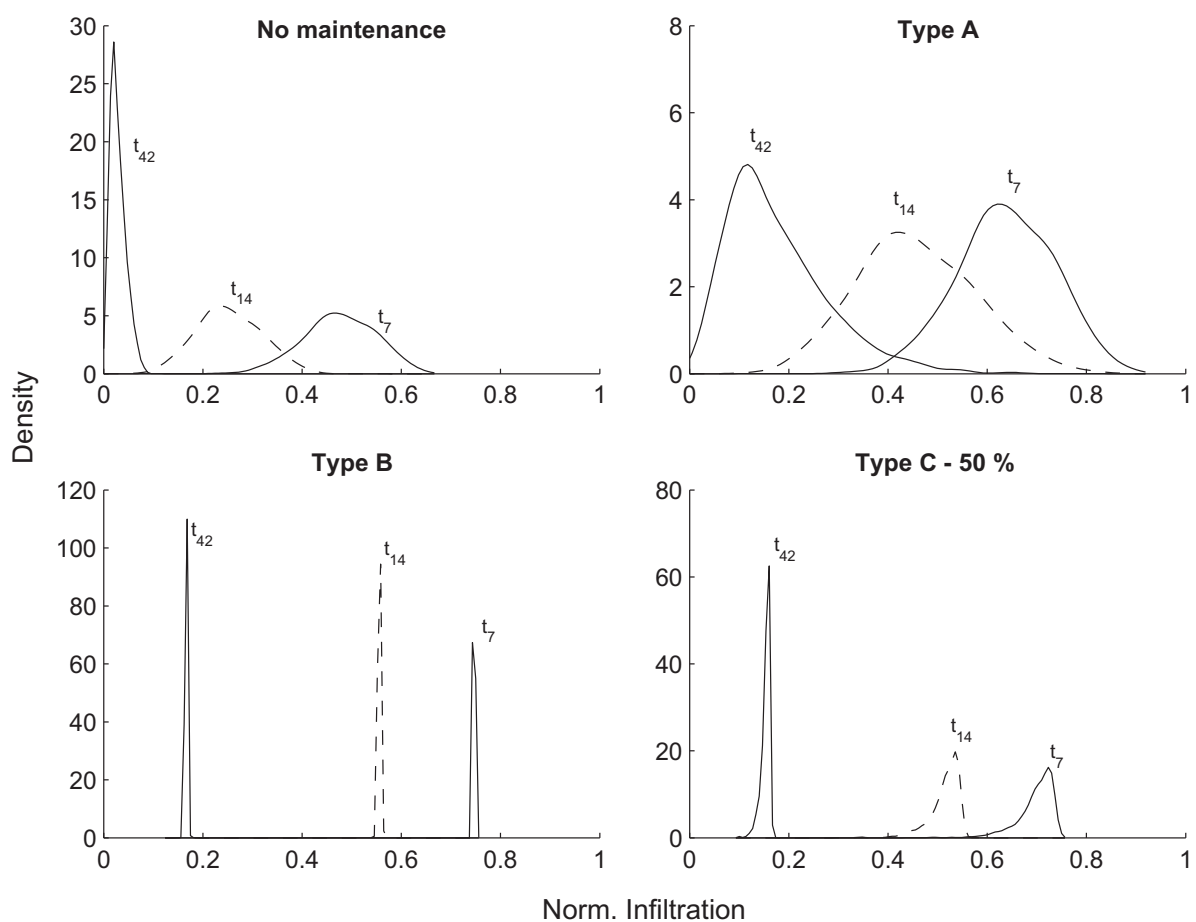

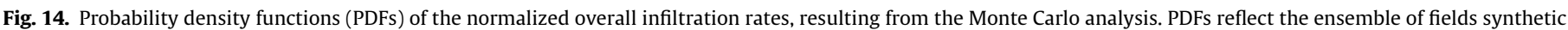
realizations with $\sigma_{Y}^{2}=4$ and $I_{S}=66$ pixels, for different types of maintenance applied on soils, at times $t_{7}=7, t_{14}=14$ and $t_{42}=42$ days.

fact that maintenance of physical clogging homogenizes the system. Interestingly, while biological processes are also heterogeneous, their range of heterogeneity is much smaller and so only treating biological processes maintains a high degree of uncertainty in the system with late time coefficients of variation in many cases reaching values of $\mathrm{O}(1)$.
Comparing physical clogging maintenance schemes $\mathrm{B}$ and $\mathrm{C}$ demonstrates that the ensemble mean behavior is practically unchanged except with a small visible difference in the most heterogeneous system where $I_{S}=66$ and $\sigma_{\mathrm{Y}}^{2}=4$. As already highlighted, the uncertainties are small for both cases with a largest value around $O\left(10^{-2}\right)$ in the most heterogeneous systems. The 
uncertainty is always smallest for Type B maintenance, which is rather intuitive since it removes all physical clogging, while $C$ only targets it partially, thus still maintaining a certain degree of physical clogging heterogeneity in the system. It is shown that biological maintenance results in the highest degree of uncertainty, which raises an important point for managers and decision makers: if dealing with a highly heterogeneous pond, one would have to decide whether to gamble with the uncertainty associated with maintenance A or take the more certain approach of maintenance against physical clogging.

To highlight the main observations from the Monte-Carlo simulations in a different way we present the cumulative distribution functions (CDF) of normalized infiltration at various times in Fig. 13. The CDFs are shown for each of the 16 cases ( 4 ponds with 4 maintenance strategies) at five different times $t_{1}, t_{7}, t_{14}, t_{21}$ and $t_{42}$, where the subscript corresponds to the number of days elapsed. In Fig. 13 the cases, which suffer from the greatest degree of uncertainty, clearly stand out (e.g. the pond with $\sigma_{Y}^{2}=4$ and $I=66$ with maintenance type A). On the contrary, many of the systems with low variance, particularly with maintenance types B and $C$ have almost instantaneous jumps in their CDFs. These sudden jumps reflect a very high degree of certainty.

Finally to convey this information even more clearly we present selected probability density functions for some specific cases to highlight particular features in Fig. 14. The PDFs are calculated as the best-fit non-parametric approximation to the discrete experimental histograms of infiltration capacities. We show the PDFs at various times for different maintenance activities, calculated for the case with greatest uncertainty $\left(I_{S}=66\right.$ pixels and $\sigma_{Y}^{2}=4 \mathrm{~m}^{2}$ / day $^{2}$ ). The PDFs are shown at three different times, $t_{7}, t_{14}$ and $t_{42}$.

The width of the PDFs reflects the degree of uncertainty and nicely visualizes some of the measures of uncertainty in Figs. 12 and 13. We would like to highlight that in Fig. 14, the shape of the pdfs for Type $C$ is clearly different from the others; this is due to the fact that the type $C$ maintenance selects to only maintain the higher infiltration rate channels, thus maintaining higher statistical mean infiltration capacity and inducing a negative skewness to the PDF. This is what increases the degree of uncertainty relative to full removal of physical clogging.

\section{Conclusions}

The effective use of Surface Infiltration Ponds (SIPs) requires the maintenance of soil infiltration capacity. Of the many processes that affect infiltration, clogging typically plays a leading role in diminishing infiltration capacity. Soil heterogeneity at SIP sites induces spatial variability of both local infiltration capacities and local clogging parameters, which complicates the accurate prediction of mean infiltration capacity.

In this work we developed a framework to evaluate the infiltration rate in a heterogeneous SIP over time so as to aid managers in the operation of a SIP under uncertainty. The framework focuses on physical, biological and retardation-like clogging mechanisms, although additional processes can easily be included. We applied our general methodology to two sets of single realization examples (a real SIP and four synthetic ones), and within a Monte Carlo framework.

The main conclusions of the work can be listed as

- We can use simplified models to quantify the reduction of soil infiltration rate due to different clogging mechanisms via characteristic grain sizes.

- Biological and physical processes combine to produce a reduction of infiltration in time. The relative impact of one versus the other is governed by some typical parameter of the soil like the grain size. A simple sensitivity analysis on the models demonstrates that physical clogging is more sensitive to soil heterogeneity than biological clogging.

- Detailed knowledge of the geological heterogeneities of the soil are a determining factor for optimal decision making in maintenance operations of SIPs. Actions can be taken aimed at reducing the impact of biological or physical clogging independently. Some of them can be selectively applied to target portions of the domain, instead of being applied over the whole domain. A proper initial characterization can significantly help to accurately predict the infiltration rate in a SIP. Such an initial characterization can for example be conducted using primary or secondary information (e.g. [36]).

- The single realization approach considers the spatial distribution of initial infiltration capacity to be fully known at any location of the pond. It demonstrates how in a heterogeneous system the mean infiltration rate can be described with an effective homogeneous decay rate despite the large degree of heterogeneity.

- The Monte Carlo framework shows that the risk of making optimal decisions depends on soil heterogeneity. Uncertainty mainly depends on the global variability of the hydraulic properties of the soil (risk of design failure increases as the variance of the hydraulic conductivity increases). The geometric distribution (evaluated by the correlation length) of such parameters also plays a role, but in most cases is secondary.

- Maintenance actions that target physical clogging mechanisms significantly reduce the uncertainty in predicting the temporal evolution of the infiltration rate relative to only maintenance in relation to biological clogging or no maintenance at all. On the other hand, some soil characterization parameter combinations lead to a larger value of the ensemble infiltration capacity with time. Thus a decision maker must weight the relative gain in infiltration capacity to the gamble of uncertainty.

\section{Acknowledgments}

This study was originated at a workshop/class taught by DMT at the Universitat Politècnica de Catalunya (UPC-Barcelona Tech). It was sponsored by the Generalitat de Catalunya. We acknowledge the financial support of the European Union and the Spanish Ministry of Science and Innovation via the 'FPU' and 'Juan de la Cierva' scholarships, the CONSOLIDER-Ingenio 2010 (CSD2009-00065), RARAAVIS (CGL2009-11114), HEROS (CGL2007-66748) programs and LIFE (LIFE $08 \mathrm{ENV/E} / 000117$ ) project. The work of DMT was supported by the Office of Science of the U.S. Department of Energy, Advanced Scientific Computing Research (ASCR) program in Applied Mathematical Sciences.

\section{References}

[1] Abu-Taleb MF. The use of infiltration field tests for groundwater artificial recharge. Environ Geol 1999;37(1-2):64-71.

[2] ASCE. Standard Guidelines for Artificial Recharge of Ground Water. Tech. rep., EWRI/ASCE 34-01 (ASCE Standard No. 34-01), 2001.

[3] Avnimelech Y, Menzel R. Biologically controlled flocculation of clay in lakes. In: Shuval H, editor, Developments in Ecology and Environmental Quality, 2nd ed., Balaban, Rehovot; 1983. p. 257-265.

[4] Barahona-Palomo M, Pedretti D, Sanchez-Vila X. Infiltration tests at the Sant Vicenç dels Horts artificial recharge experimental site, in: EGU General Assembly 2010, Geophysical Research Abstracts, vol. 12 of EGU2010-5326; 2010.

[5] Batchelor B, Valdes J, Araganth V. Stochastic risk assessment of sites contaminated by hazardous wastes. J Environ Eng 1998;124:380-8.

[6] Baveye P, Valocchi VA. An evaluation of mathematical models of the transport of biologically reacting solutes in saturated soils and aquifers. Water Resour Res 1989;25(6):1413-21.

[7] Baveye P, Vandevivere P, Hoyle BL, DeLeo PC, de Lozada-Sanchez D. Environmental impact and mechanisms of the biological clogging of saturated soils and aquifer materials. Critical Rev Environ Sci Tech 1998;28(2):123-91. 
[8] Bedford T, Cook R. Probabilistic risk analysis: foundations and methods. Cambridge University Press; 2001.

[9] Bolster D, Barahona-Palomo M, Dentz M, Fernàndez-Garcia D, Sanchez-Vila X Trinchero $\mathrm{P}$, et al. Probabilistic risk assessment applied to contamination scenarios in porous media. Water Resour Res 2009;45(W06413). doi:10.1029 2008WR007551.

[10] Bouwer H. Artificial recharge of groundwater: hydrogeology and engineering. Hydrogeol J 2002;10(1):121-42.

[11] Boyd RH, Ghosh MM. An investigation of the influence of some physicochemical variables on porous-media filtration. J Am Water Works Assn 1974;66(2):94-8.

[12] Brooks RH, Corey AT. Hydraulic properties of porous media: Colorado St Univ Hydrol Paper, 1964;27(3).

[13] Carman P. The determination of the specific surface of powders. J Soc Chem Ind Trans $1938 ; 225(57)$

[14] CGWB. Manual of artificial recharge of ground water. Tech. rep. Government of India. Ministry of water resources. Central Ground Water Board. New Delhi. 2007.

[15] Chapuis RP, Aubertin M. On the use of the Kozeny-Carman equation to predict the hydraulic conductivity of soils. Canadian Geotech J 2003;40(3):616-28.

[16] Chang YI, Cheng WY, Chan HC. A proposed correlation equation for predicting filter coefficient under unfavorable deposition conditions. Sep Purif Technol 2009;65(3):248-50.

[17] Christiansen JE. Effect of entrapped air upon the permeability of soils. Soil Sci 1944;58(5):355-66

[18] Civan F. Non-isothermal permeability impairment by fines migration and deposition in porous media including dispersive transport. Transp Porous Med 2010;85(1):233-58. doi:10.1007/s11242-010-9557-0.

[19] Civan F, Nguyen V. Modeling particle migration and deposition in porous media by parallel pathways with exchange. In: Vafai K, editor. Handbook of porous media. Boca Raton, FL: CRC Press; 2005. p. 457-84.

[20] Civan F, Rasmussen ML. Analytical models for porous media impairment by particles in rectilinear and radial flows. In: Vafai K, editor. Handbook of porous media. Boca Raton, FL: CRC Press; 2005. p. 485-542.

[21] Clement TP, Hooker BS, Skeen RS. Macroscopic models for predicting changes in saturated porous media properties caused by microbial growth. Ground Water 1996;34(5):934-42.

[22] de Barros FPJ, Rubin Y. A risk-driven approach for subsurface site characterization. Water Resour Res 2008;44(W01414).

[23] de Barros FPJ, Bolster D, Sanchez-Vila X, Nowak W. A divide and conquer approach to cope with uncertainty, human health risk and decision making in contaminant hydrology. Water Resour Res 2011;47(W05508).

[24] Dillon P, editor. Management of aquifer recharge for sustainability: proceedings of the 4th international symposium on artificial recharge of groundwater, Adelaide, Sep 2001. New York: Taylor \& Francis; 2002.

[25] Drazen A, Helpman E. Economic effects on the government budgets. In: Helpman E, Razin A, Sadka E, editors. Stabilization with exchange rates management under uncertainty. Boston: MIT Press; 1998. chap. 16.

[26] Ernisee JJ, Abott WH. Binding of mineral grains by a species of Thalassiosira. Nova Hedwigia Beih 1975;53:241-52.

[27] Fry VA, Istok JD, Semprini L, O'Reilly KT, Buscheck TE. Retardation of dissolved oxygen due to a trapped gas phase in porous media. Ground water 1995;33(3):391-8.

[28] Gomez-Hernandez J, Journel A. Joint sequential simulation of multi-Gaussian fields. In: Soares A, editor. Geostat Troia 1992, vol. 1. Dordrecht, Netherlands: Kluwer; 1993. p. 85-94.

[29] Greskowiak J, Prommer H, Massmann G, Johnston CD, Nützmann G, Pekdege A. The impact of variable saturated conditions on the hydrochemistry during artificial recharge of groundwater - A field study. Appl Geochem 2005;20:1409-26.

[30] Hazen A. Some physical properties of sands and gravels, with special reference to their use in filtration, 24th Annual Rep., Massachusetts State Board of Health, Pub. Doc. 1982;34:539-556.

[31] Iwasaki T. Some notes on sand filtration. J Am Water Works Assn 1937;29: 1597-602.
[32] Kozeny J. Über kapillare Leitung des Wassers im Boden. Sitzungsber Akad Wiss Wien 1927;136:271-306.

[33] NRC, Ground Water Recharge Using Waters of Impaired Quality, Tech. rep., National Research Council, Committee on Ground Water Recharge, Water Science and Technology Board, Commission on Geosciences, Environment, and Resources., National Academy Press, Washington, D.C. 1994.

[34] NRC, Review of recommendations for probabilistic seismic hazard analysis: Guidance on uncertainty and use of experts, Tech. rep., National Research Council, Natl. Acad. Press, Washington, D.C. 1997.

[35] Orr S, Meystel AM. Approaches to optimal aquifer management and intelligent control in a multiresolutional decision support system. Hydrogeol J 2005;13(1):223-46.

[36] Pedretti D, Barahona-Palomo M, Bolster D, Fernàndez-Garcia D, Sanchez-Vila $\mathrm{X}$. Spatial assessment of infiltration capacity of soils for artificial recharge practices using Google Earth images. Proceedings of the GeoEnV Conference, Ghent University, Ghent, Belgium. 2010.

[37] Pedretti D, Fernàndez-Garcia D, Sanchez-Vila X, Barahona-Palomo $M$, Bolster D. Combining physical-based models and satellite images for the spatiotemporal assessment of soil infiltration capacity. Stochast Environ Res Risk Asses 2007;1436-3240:1-11. doi:10.1007/s00477-011-0486-4.

[38] Perez-Paricio A. Integrated model of clogging processes in artificial groundwater recharge. Doctoral thesis. Department of Geotechnical Engineering and Geosciences, Technical University of Catalonia (UPC), Barcelona. 2000.

[39] Perez-Paricio A, Carrera J. Clogging handbook. Tech. rep., Final report, EU project on Artificial Recharge of Groundwater. 1999.

[40] Rosowski JR, Hoagland K, Aloi J. Structural morphology of diatom-dominated stream biofilm communities under the impact of soil erosion. In: Evans LV, Hoagland K, editors. Algal biofouling. Amsterdam, The Netherlands: Elsevier; 1986. p. 247-97.

[41] Scanlon BR, Keese KE, Flint AL, Flint LE, Gaye GB, Edmunds WM, et al. Global synthesis of groundwater recharge in semiarid and arid regions. Hydrol Processes 2006;20:3335-70.

[42] Smith R. The infiltration envelope: results from a theoretical infiltrometer. J Hydrol 1972;17:1-21.

[43] Tartakovsky DM. Probabilistic risk analysis in subsurface hydrology. Geophys Res Lett 2007;24(L05404). doi:10.1029/2007GL029245.

[44] Tartakovsky DM, Winter CL. Uncertain future of hydrogeology. ASCE J 394 Hydrologic Eng 2008;13(1):37-9.

[45] Tien C, Payatakes AC. Advances in deep bed filtration. AIChE J 1979;25(5): 737-59.

[46] Tufenkji N, Elimelech M. Correlation equation for predicting single-collector efficiency in physicochemical filtration in saturated porous media. Environ Sci Technol 2004;38(2):529-36.

[47] Tuinhof A, Heederik JP, editors. Management of aquifer recharge and subsurface storage. Netherlands national committee - international association of hydrogeology, vol. 4. NNCIAH Publication; 2003.

[48] van Genuchten MT. A closed-form equation for predicting hydraulic conductivity of unsaturated soils. Soil Sci Soc Am J 1980;44:892-8.

[49] Vandevivere P, Baveye P, de Lozada DS, DeLeo P. Microbial clogging of saturated soils and aquifer materials: evaluation of mathematical models. Water Resour Res 1995;31(9):2173-80.

[50] Wagner B, Gorelick S. Optimal groundwater quality management under parameter uncertainty. Water Resour Res 1987;23(7):1162-74.

[51] Wang T, McTernan WF. The development and application of a multilevel decision analysis model for the remediation of contaminated groundwater under uncertainty. J Environ Manage 2002;64:221-35.

[52] Zamani A, Maini B. Flow of dispersed particles through porous media - Deep bed filtration. J Petrol Sci Eng 2009;69:71-88.

[53] Zenios SA, Holmer RM, McKendall R, Vassiadou-Zeniou C. Dynamic models for fixed-income portfolio management under uncertainty. J Econ Dynam Control 1998;22(10):1517-44.

[54] Zwietering $\mathrm{MH}$, Jongenburger I, Rombouts FM, van T Riet K. Modeling of the bacterial growth curve. Appl Environ Microbiol 1990;56(6): 1875-81. 